\title{
The Effect of Wind Loads on the Seismic Performance of Tall Buildings
}

\author{
By Shilpa Nirman Thilakarathna* \\ Naveed Anwar ${ }^{\dagger}$ \\ Pramin Norachan \\ Fawad Ahmed Naja
}

\begin{abstract}
Wind and earthquake loadings are the two major types of lateral dynamic excitations experienced by high-rise buildings. An efficient design must ensure the safety of structural and non-structural components of a building against both types of loadings. This study evaluates the seismic performance of high-rise buildings primarily designed based on different levels of lateral wind loads. A 40-story dual system case study building is selected for this purpose. In dual systems, the lateral load is mainly resisted by a combination of reinforced concrete core wall and the special moment resisting frame. The case study building is assumed to be located in a moderate-level seismic zone and is separately designed for wind loading using three different levels of wind speeds (low, moderate and high), which are selected to represent the anticipated hazards at various global wind zones. The detailed seismic performance exhibited by three different design cases (corresponding to different levels of wind hazard) is evaluated. The Nonlinear Response History Analysis (NLRHA) procedure is used to obtain the true inelastic seismic demands and to compare the seismic performance of all three design cases. The results showed that the level of design wind load can alter the seismic performance of high-rise dual system buildings. Therefore, even for the cases where the wind demands control the design of lateral load-resisting system, the detailed performance-based seismic evaluation should be carried out to ensure the overall structural safety and integrity.
\end{abstract}

Keywords: Dual systems, High-rise buildings, Performance-based seismic evaluation, Wind loading.

\section{Introduction}

Since the last couple of decades, tall buildings are gaining popularity around the metropolitan areas due to their economic advantages as well as sustainability considerations. With growing height and slenderness, the seismic and wind loads have become a major consideration in design and evaluation of high-rise buildings. An ideal structural system for wind design can be described as a solid, heavy system with strong connections which helps to resist loads as the wind blows across and over the structure. On the other hand, when seismic load is applied to the building, it experiences cyclic loading as the building's inertia

*MS Graduate, Asian Institute of Technology (AIT), Thailand.

${ }^{\dagger}$ CEO, AIT Solutions, Affiliated Faculty, Asian Institute of Technology (AIT), Thailand.

${ }^{\star}$ Head, Structural Engineering, AIT Solutions, Asian Institute of Technology (AIT), Thailand.

-Assistant Professor, National University of Sciences and Technology (NUST), Pakistan. 
catches up with the ground movement. So, the building is designed to efficiently dissipate the seismic energy through damping and yielding of the structural components.

In strong wind terrain, when traditional design codes are employed, the wind demands can be higher than the seismic design demands, and therefore, can control the design. However, studies have shown that the true nonlinear seismic demands can be significantly higher than those predicted by the code-based Response Spectrum Analysis (RSA) (Ahmed, 2011; Ahmed and Warnitchai, 2012). This observation may invoke the need of seismic performance evaluation of buildings originally designed to wind. This integrated approach to assess the structural performance for both types of loadings is investigated by various researchers. Adnan and Suradi (2008) studied the performance of wind-designed $\mathrm{RC}$ buildings in Malaysia against the earthquake loads. The buildings were originally designed for wind with a design speed of $30 \mathrm{~m} / \mathrm{s}$ to $40 \mathrm{~m} / \mathrm{s}$ using the static analysis procedure. However, the detailed results show that these buildings were unable to perform well under lateral loads even at low seismic intensities. More recently, Aly and Abburu (2015) conducted a full dynamic case study to observe the behavior of high-rise buildings against earthquake and wind loads while assessing the basic difference between seismic and wind demands. The two tall buildings (76- and 54-story) were examined against seismic and wind hazard using the Nonlinear Response History Analysis (NLRHA) and wind tunnel test, respectively. It was reported that the high-rise buildings designed for high wind were safe against moderate-level earthquake forces. Hoang (2011) analyzed a 40-story RC core wall building located in Hanoi, Vietnam according to ASCE 7-02 and UBC 97 codes for low to moderate seismic levels. Moderatelevel wind responses were determined according to the guidelines provided by the Architectural Institute of Japan (AIJ). The detailed NLRHA procedure was conducted for the maximum considered earthquake (MCE). It was observed that the true seismic demands computed by the NLRHA procedure were higher than both the wind and seismic demands computed by the code-based methods.

\section{Methodology}

In this study, a comparison between the seismic performances of three separate design cases (each corresponding to a specific wind hazard level) is presented. For this purpose, three levels of design wind loads (i.e. low, moderate and high load) were selected which are expected to represent various real scenarios of combinations of wind and seismic hazards in countries prone to both hazard types.

A 40-story RC core wall building located in a moderate seismic region (Bangkok, the capital city of Thailand) is selected to determine the effect of design wind loads on its seismic performance. Bangkok has long been considered free from seismic risk. Recent studies, however, have shown that the city is at risk from moderate seismic risk from distant large-magnitude earthquakes. Moreover, the soft soil deposits have the tendency to amplify ground motions 
around 3 to 4 times. Prior to this new understanding, the code-prescribed designbasis earthquake loading is considered lower than the wind loads. Therefore, most of the existing high-rise buildings in Bangkok were primarily designed for wind loads without considering significant seismic action and ductile detailing requirements. This demands to carry out the seismic performance evaluation for existing buildings.

The structural performance of selected case study building is evaluated for Design basis earthquake (DBE) and Maximum considered earthquake (MCE) levels (Moehle, 2008; Naeim, 2010). The DBE-level earthquake is generally defined in seismic evaluation guidelines as the earthquake with $10 \%$ probability of exceedance in 50 years. The performance objective for this level is that the structure should ensure life safety. The MCE-level earthquake is usually defined as the earthquake with a $2 \%$ probability of exceedance in 50 years. In order to satisfy the performance objective for this hazard level, the structure should not collapse, however it may undergo a certain acceptable level of damage (Chopra, 2007; CTBUH, 2016).

The seismic demands of the case study building were determined using the standard RSA procedure for DBE-level response spectrum. The wind demands were computed using the gust factor method and were compared with those obtained from the standard RSA procedure. The structural members were designed based on the maximum demands obtained by either of wind or earthquake load combinations. Then, the building is evaluated for the MCE-level seismic hazard which was considered as 1.5 times the DBE-level. The detailed NLRHA procedure was performed to evaluate the seismic performance using a set of ground motion records scaled to MCE-level spectrum.

\section{Description of the Case Study Building}

The case study building was originally designed by the Magnusson Klemencic Associates and Arup according to LATBDSC (2005) (Klemencic et al., 2006; 2007; Zekioglu et al., 2007) and this building was expected to be positioned in downtown Los Angeles which is reported as a high seismic region. For this study, the primary lateral load resisting system of this building is changed from the core wall with post-tensioned slab to core wall with moment resisting frame. Moreover, the element sizes are also modified according to the governing load combination in each case (i.e. the maximum of high-, low- or moderate-wind and the moderate-level seismic forces).

The lateral load resisting system mainly comprises of a central RC core wall and the moment resisting frame. The gravity load carrying system includes a slab and beam system which rests on peripheral columns and on the central core. The Table 1 shows the salient features of the case study building, while Figure 1 shows its typical floor plans. It can be seen that there are four openings in the Y direction and one opening in the $\mathrm{X}$ direction at each floor level of the core wall. The coupling beams were used to connect these wall segments. 
Figure 1. The Typical Building Floor Plans

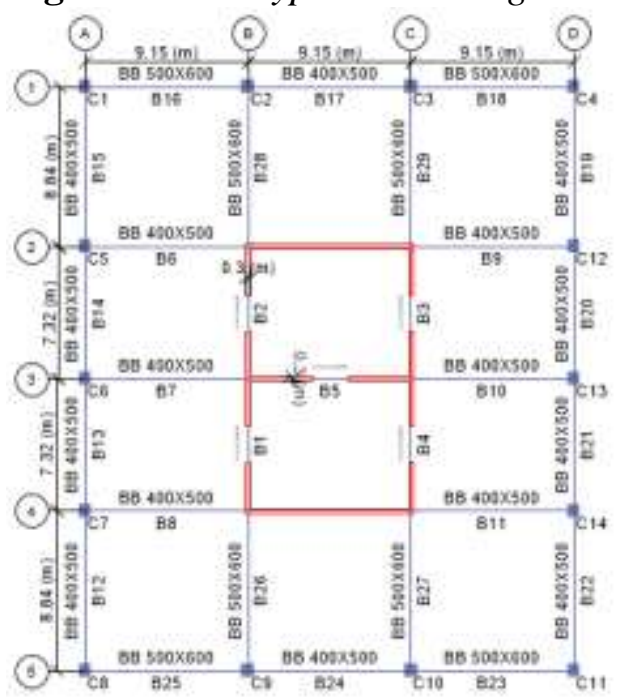

(a) $1^{\text {st }}$ story to $20^{\text {th }}$ story

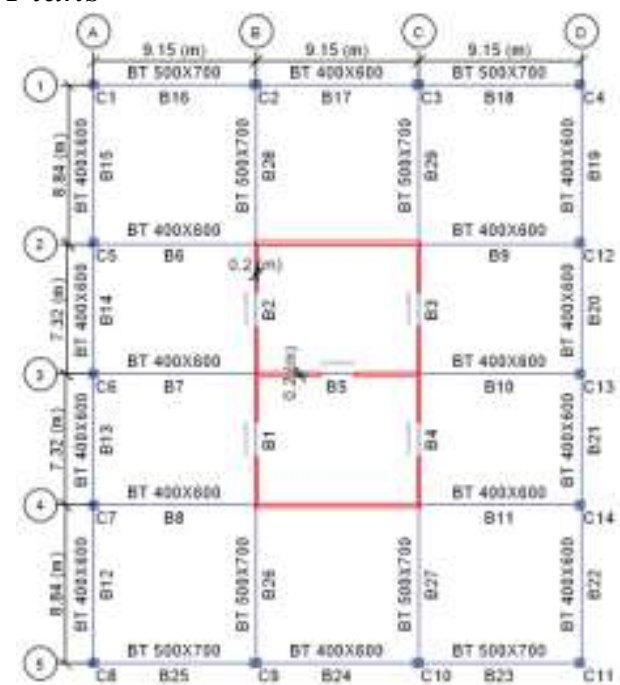

(b) $21^{\text {st }}$ story to $40^{\text {th }}$ story

Table 1. The Dimensions and Salient Features of the Case Study Building

\begin{tabular}{lll}
\hline Details & & Dimensions \\
\hline Number of stories & & 40 \\
Total Height $(\mathrm{m})$ & & 129 \\
1st story height $(\mathrm{m})$ & & 6.1 \\
Typical story height $(\mathrm{m})$ & & 3.15 \\
Floor area $\left(\mathrm{m}^{2}\right)$ & 887.18 \\
Core wall thickness $(\mathrm{mm})$ & Base -20 & 300 \\
& $21-40$ & 200 \\
Column sizes $(\mathrm{mm})$ & Base -10 & $800 \times 800$ \\
& $11-20$ & $700 \times 700$ \\
& $21-30$ & $600 \times 600$ \\
Coupling beams $(\mathrm{mm})$ & $31-40$ & $500 \times 500$ \\
& 1 & $300 \times 1700$ \\
Slab thickness $(\mathrm{mm})$ & $2-20$ & $300 \times 900$ \\
Concrete density $\left(\mathrm{kg} / \mathrm{m}^{3}\right)$ & $21-40$ & $200 \times 700$ \\
Concrete $f_{c}^{\prime}(\mathrm{MPa})$ & $1-40$ & 200 \\
& Base -40 & 2400 \\
Concrete $E_{c}(\mathrm{MPa})$ & Base -20 & 55.16 \\
& $21-40$ & 41.37 \\
Steel $f_{y}(\mathrm{MPa})$ & Base -20 & 34906 \\
Steel $E_{s}(\mathrm{MPa})$ & $21-40$ & 30230 \\
Super Dead Load $\left(\mathrm{KN} / \mathrm{m}^{2}\right)$ & Base -40 & 413.6 \\
Live Load $\left(\mathrm{KN} / \mathrm{m}^{2}\right)$ & Base - 40 & 199948 \\
& $1-40$ & 1.5 \\
& $1-40$ & 2.5 \\
\hline
\end{tabular}

All the building elements were designed to obtain reinforcement except slabs. For the linear and nonlinear evaluation purpose, elements were selected considering the building geometry and the variation of the force demand. 
Considering shear wall flexure, all the piers are considered and for the shear force evaluation few sub piers are selected. All the coupling beams are considered for evaluation, because coupling beams are more critical in this building model. The six columns and eight beam positions which were selected on the plan view and element from base to top were considered for the evaluation. The axial strain gauges elements were used in the analytical model at various selected locations for recording the axial strains in different elements.

\section{The Wind and Seismic Loadings}

The design spectrum (5\% damped) and other seismic design parameters was obtained from the Thailand seismic standard (DPT 1302, 2009) for the moderate hazard zone. The ASCE 7-10 was used as the main design code for the RSA analysis. A linear elastic 3D finite element model was created and analyzed using ETABS 2015 (CSI, 2016). The modal properties (natural periods, mode shapes, and modal mass participation factors) of all significant vibration modes were obtained in each principal horizontal direction (X and $\mathrm{Y}$ ). The number of significant modes representing at least 90 percent of the cumulative participating mass of the building were considered. The elastic responses of all significant vibration modes were obtained and combined into the total responses by the SRSS method. Then, the combined force demands are reduced by the response modification factor ' $R$ ' to obtain the seismic design demands. The $R$ factor of 6 was selected according to the classification of "dual system with special moment frame" in ASCE 7-10. The design base shear demand obtained from the RSA procedure should not be less than 85 percent of the design base shear determined by the equivalent static force procedure. The RSA results were scaled as per this condition.

Three wind design parameters for low, moderate and high levels; $20 \mathrm{~m} / \mathrm{s}$, $40 \mathrm{~m} / \mathrm{s}$ and $55 \mathrm{~m} / \mathrm{s}$ (3 second gust speed in 50-year return period) respectively (Holmes, 2017) (Figure 2). According to the Thailand's DPT 1302 standards, Bangkok has a mean wind speed of $38 \mathrm{~m} / \mathrm{s}$ ( $25 \mathrm{~m} / \mathrm{s}$ hourly mean) which also closer to the selected wind speed for moderate level. The estimation of gust response factor was carried out according to ASCE 7-10.

Figure 2. The Selection of Wind Load Levels

\begin{tabular}{|c|c|c|c|}
\hline Level & $\begin{array}{l}\text { 3-second gust } \\
(\mathrm{m} / \mathrm{s})\end{array}$ & & \\
\hline I & $<35$ & Low wind speed & $20 \mathrm{~m} / \mathrm{s}$ \\
\hline II & $35-45$ & & \\
\hline III & $45-55$ & Moderate wind speed & $40 \mathrm{~m} / \mathrm{s}$ \\
\hline IV & $55-65$ & Hish wind soeed & \\
\hline $\mathbf{V}$ & $>65$ & Mign wina speed & \\
\hline
\end{tabular}

The load combinations as prescribed in the ASCE 7-10 were used to design the reinforcement for columns, shear walls, coupling beams and girders. Both 
the global and local responses were obtained from the linear elastic analysis. The case study structure is checked for the allowable displacement and drift limits against both wind and seismic force. Moreover, base shear, story shear, overturning moment is also compared. The serviceability check is also applied using the following criterion. For wind, the story drift $\leq 0.4 \%$, while the lateral displacement $\leq \mathrm{H} / 400$ (10-year return period wind). For seismic, the inter-story drift $\leq 2 \%$. The demand-to-capacity ratios $(\mathrm{D} / \mathrm{C})$ ratios for different structural members were also determined for each analysis case and used to check the performance.

\section{The Nonlinear Modeling Considerations}

For conducting the detailed NLRHA procedure, the full nonlinear 3D models were created in PERFORM 3D (CSI, 2006). The column, shear walls, coupling beams and girders are modeled as nonlinear elements but slab is modeled as elastic linear.

Figure 3.The Nonlinear Modeling of Structural Components

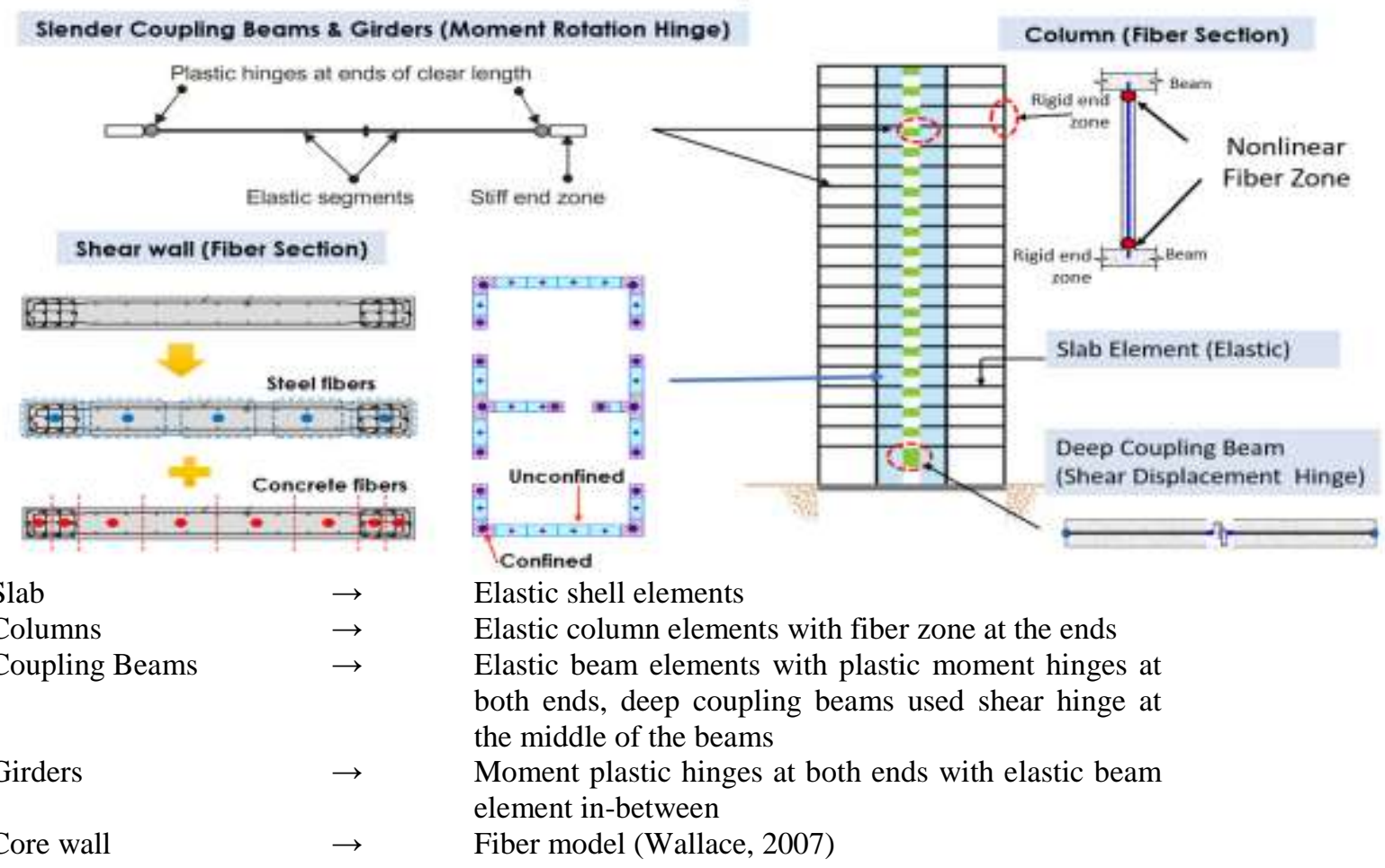

In RC beams, the nonlinearity in flexural action is captured using the moment-rotation type plastic hinges (ASCE 41-06, 2006) at the beam ends while a linear elastic frame element is used in between. The shear behavior is assumed to remain linear elastic. However, shear force demands were compared with corresponding strength capacities after the analysis to check shear failure. Figure 3 shows the summary of nonlinear modeling approaches used for each type of structural component. 
The shear walls were modeled using the nonlinear fiber modeling approach throughout the whole height of the structures (Wallace, 2007). In fiber element modeling, an adequate amount of concrete and steel fibers are used to capture the realistic strain distribution across the members' cross-sections. The stress-strain relationship for nonlinear materials are assigned to each fiber. The steel fibers are modeled using the Park's model, while concrete is modeled using the Mander's model (1988).

\section{The Selection of the Ground Motion Records}

The ground motions matching with the specific site conditions are selected from the PEER NGA and COSMOS databases (PEER, 2005; COSMOS, 1999). The MCE response spectrum is calculated to be 1.5 times the $5 \%$-damped DBE response spectrum and all the ground motion records were spectrally matched (Hancock et al., 2006) to this target response spectrum. Figure 4 shows the spectra of selected ground motion records which are matched to 1.5 times the DBE-level uniform hazard spectrum (UHS) for Bangkok.

\section{Acceptance Criteria}

For the deformation controlled actions, the deformation capacities are calculated using the expected material properties and strength reduction factor of 1.0. The results are checked for mean value of demand from seven sets of ground motion records. For the force controlled actions, the critical actions are defined as the actions in which failure mode poses severe consequences to structural stability under gravity and/or lateral loads. For this purpose, 1.5 times the mean value of demand from seven sets of ground motions is used. The capacity is calculated using expected material strength and strength reduction factor of 1 . Table 2 shows the acceptance criterion used in this study.

Figure 4. Spectrum Matched Ground Motion Records

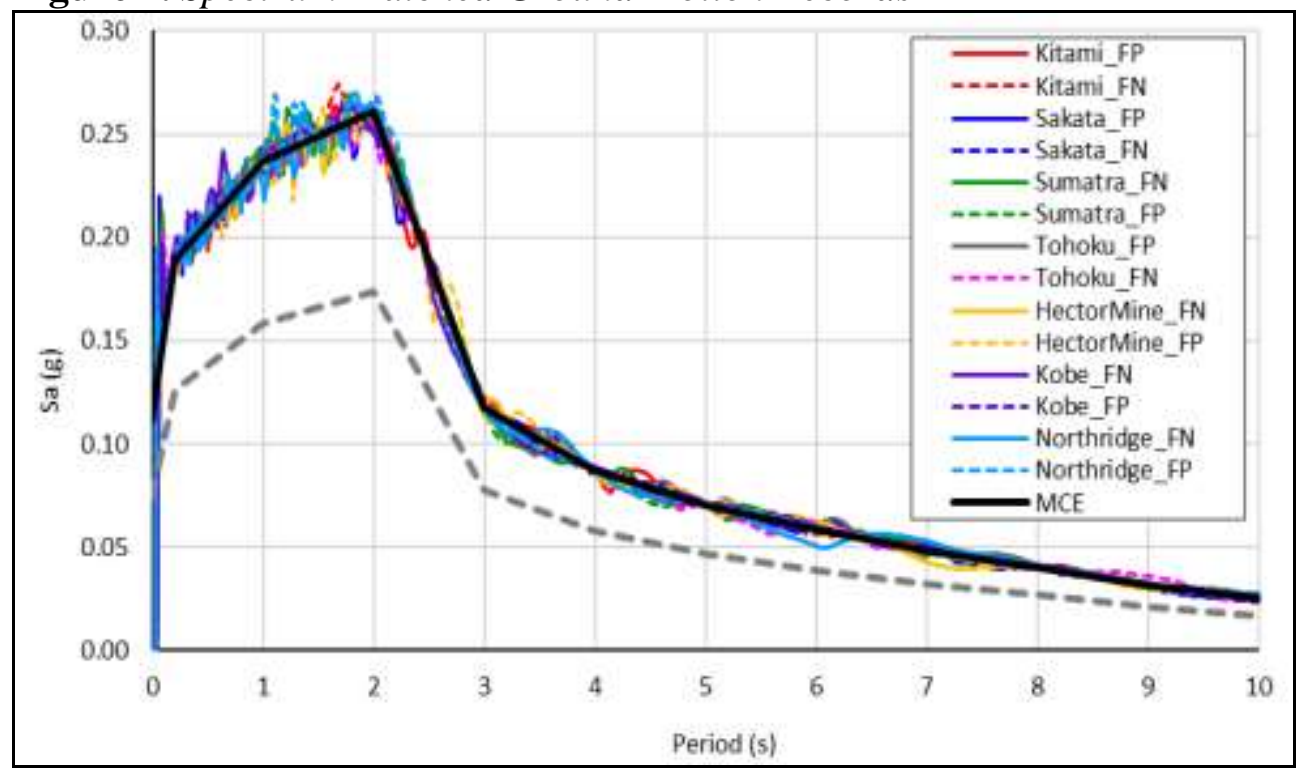


Table 2. The Acceptance Criteria for Maximum Considered Earthquake (MCE)

\begin{tabular}{ll}
\hline Item & Value \\
\hline Peak transient drift & Maximum of mean values shall not exceed 3\%. \\
& $\begin{array}{l}\text { Maximum drift shall not exceed 4.5\%. } \\
\text { Maximum of mean values shall not exceed 1\%. } \\
\text { Residual drift }\end{array}$ \\
$\begin{array}{l}\text { Maximum drift shall not exceed 1.5\%. } \\
\leq \text { ASCE 41-13 limits }\end{array}$ \\
$\begin{array}{l}\text { Coupling beam inelastic } \\
\text { rotation }\end{array}$ & $\leq$ ASCE 41-13 limits \\
$\begin{array}{l}\text { Column Inelastic Rotation } \\
\text { Shear wall reinforcement } \\
\text { axial strain }\end{array}$ & $\leq 0.05$ in tension and $\leq 0.02$ in compression \\
Shear wall shear & Remain elastic. (Check for 1.5 times mean value) \\
Girder inelastic rotation & $\leq$ ASCE 41-13 limits \\
Girders shear & Remain elastic.
\end{tabular}

\section{The Code-based Design of Case Study Building}

Three building models were considered for the linear analysis corresponding to three combinations of wind load levels and a selected moderate seismic level, as follows.

a) Moderate-level seismic load and low-level wind load - Model 01

b) Moderate-level seismic load and moderate-level wind load - Model 02

c) Moderate-level seismic load and high-level wind load - Model 03

After the design, the three corresponding nonlinear structural models were developed for detailed performance evaluation and analyzed separately.

\section{Comparison of Global Seismic Demands}

Figure 5 shows the first three vibration mode shapes their natural periods. First, second and third modes are translational in $\mathrm{X}$ direction, translational in $\mathrm{Y}$ direction and the torsion, respectively.

Figure 6 shows the (a) base shear demands, and the (b) base shear coefficient (the value normalized by the total seismic weight of the building, expressed as percentage) for all three building models corresponding to the combinations of wind and earthquake loadings in both directions. The base shear demand for earthquake load is same for each model as only one constant seismic level is considered, while the base shear demands for wind are decreasing with the reduced wind hazard considered. For the case corresponding to low wind level, the base shear demands for wing are lower than the seismic base shear obtained by the equivalent lateral force procedure and the RSA procedure. 
Figure 5.Mode Shapes and Relevant Mode Number with the Periods
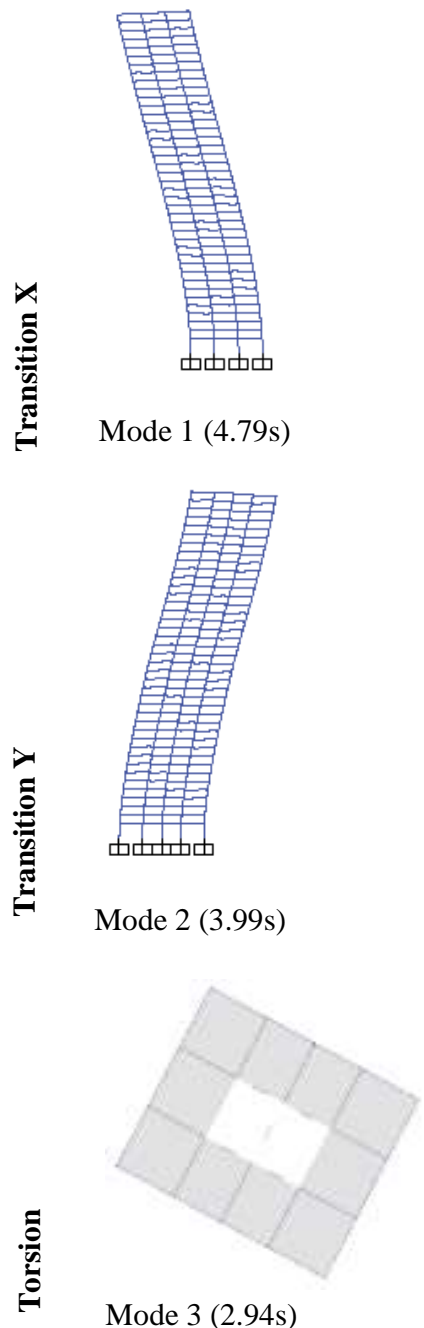

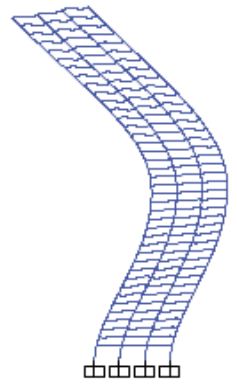

Mode 4 (1.17s)

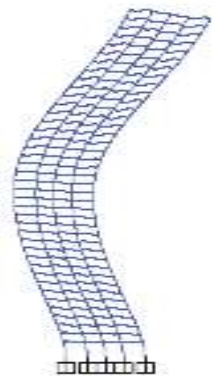

Mode $5(1.11 \mathrm{~s})$

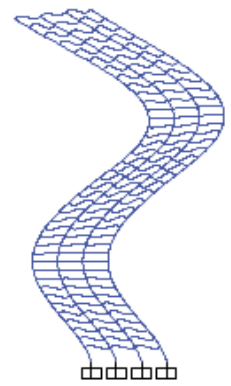

Mode $9(0.51 \mathrm{~s})$

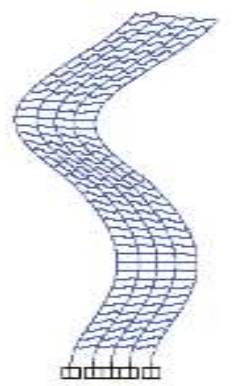

Mode 8 (0.56s)
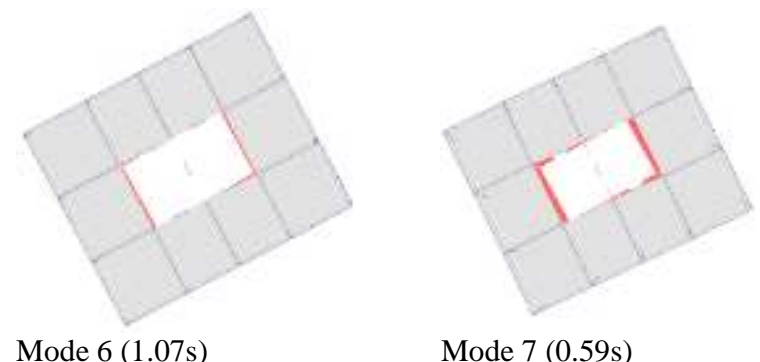

Mode 7 (0.59s)

Figure 6. The Base Shear Values in X and Y Directions

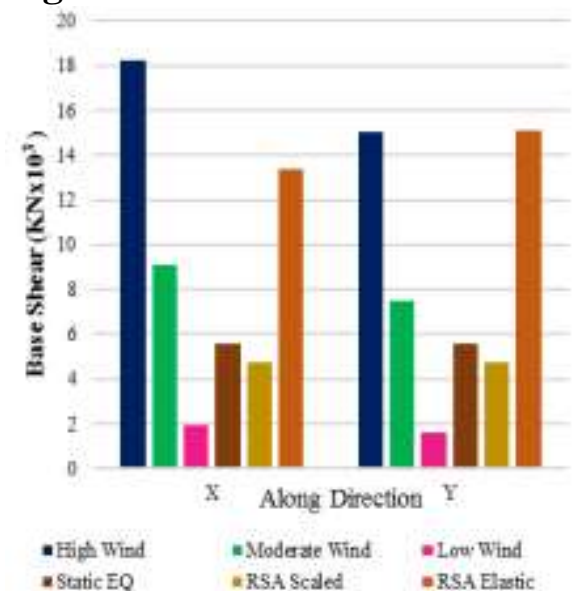

(a) Base shear

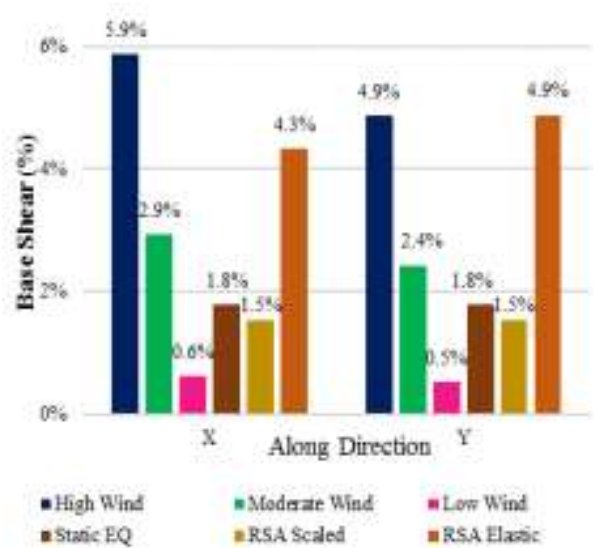

(b) Base shear normalized to the total seismic weight of the building 
The story shear forces for both wind and earthquake (RSA) are shown in the Figure 7(a) for all three building models in both $\mathrm{X}$ and $\mathrm{Y}$ directions. For each model, it can be seen that the story shear for wind in its $\mathrm{X}$ axis is higher than the $\mathrm{Y}$ axis. Story shear for wind tends to gradually decrease when the wind level is decreasing and for the lowest wind level considered, it is smaller than the story shear values for earthquake. This pattern is almost similar for both $\mathrm{X}$ and $\mathrm{Y}$ axis for each building model. However, in the building model 02 , the story shear for earthquake surpasses the story shear for wind approximately beyond the story level 30 and 25 in $\mathrm{X}$ axis and $\mathrm{Y}$ axis, respectively. In each model for both $\mathrm{X}$ and $\mathrm{Y}$ axis, the story shear for earthquake remains the same because RSA results were scaled to $85 \%$ of those obtained from the equivalent static force procedure. Figure 7(b) shows the distribution of story moment about $\mathrm{Y}$ and $\mathrm{X}$ axis which tend to follow the same pattern as the story shear. However, the story moment for earthquake surpasses the story moment for moderate wind approximately beyond the level 25 and 15 about $\mathrm{Y}$ and $\mathrm{X}$ axis, respectively.

Figure 7. The Distribution of the (a) Story Shear and the (b) Overturning Moment in the Three Building Models

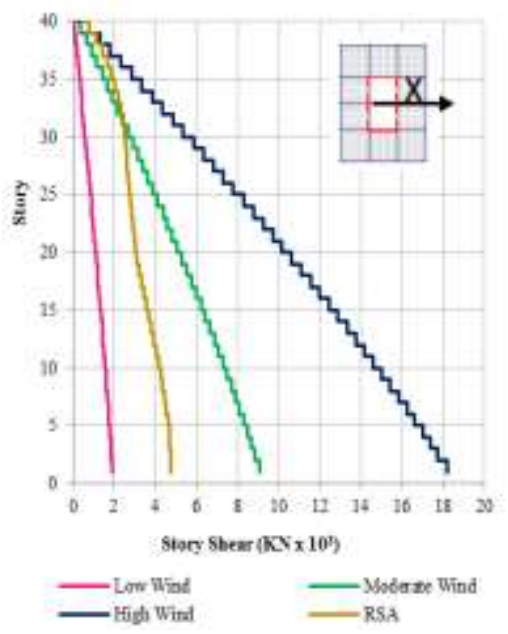

(a) Story shear in $\mathrm{X}$ and $\mathrm{Y}$ directions
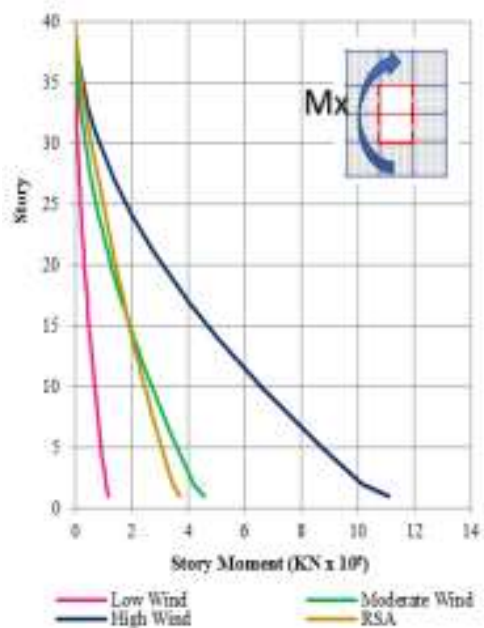
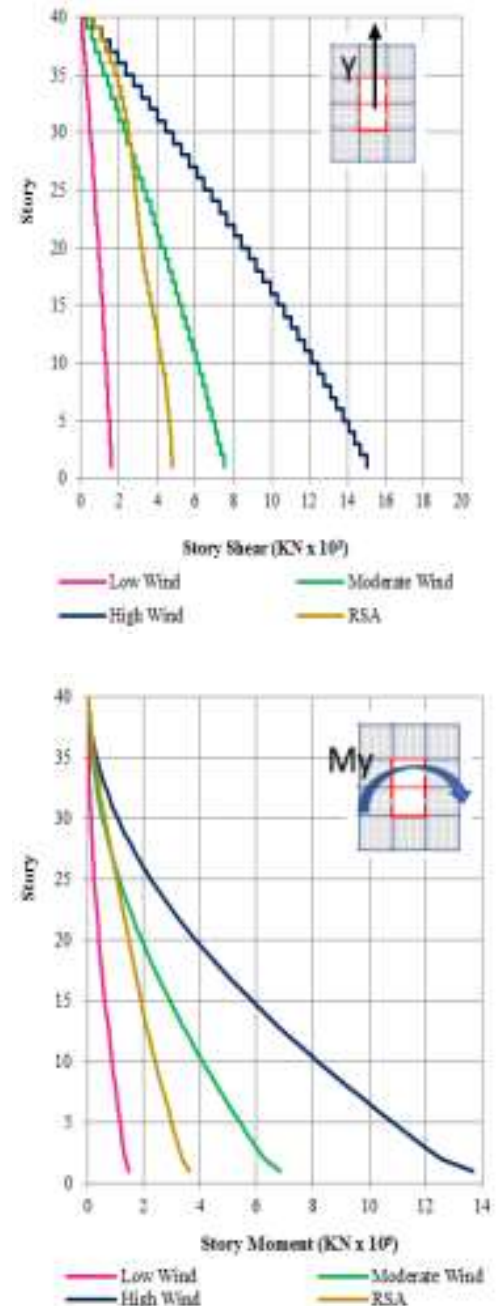

(b) Overturning moments in $\mathrm{X}$ and $\mathrm{Y}$ directions 
Story drift and displacement demands for the wind in both $\mathrm{X}$ and $\mathrm{Y}$ axis on the three building models are presented in the Figure 8. Both story drift and displacement in the $\mathrm{X}$ axis is greater than the $\mathrm{Y}$ axis and they are gradually decreasing with the decreasing wind level. However, both story drift and displacement stay within the allowable limit. Table 3 shows allowable displacement and drift limits for wind and earthquake in both $\mathrm{X}$ and $\mathrm{Y}$ direction.

Figure 8. Story Drifts and Displacement Demands in X and Y Axis
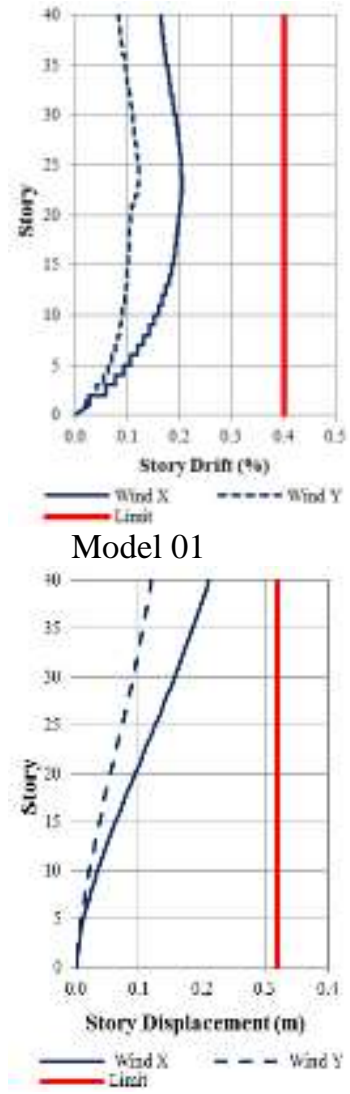

Model 01
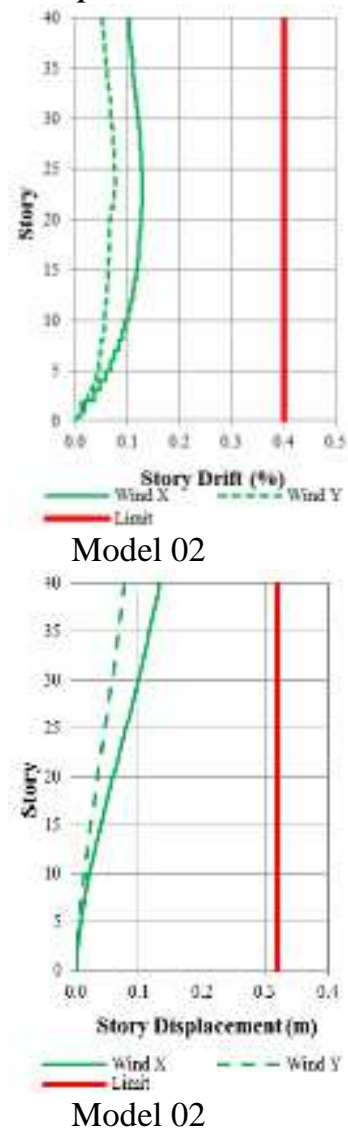

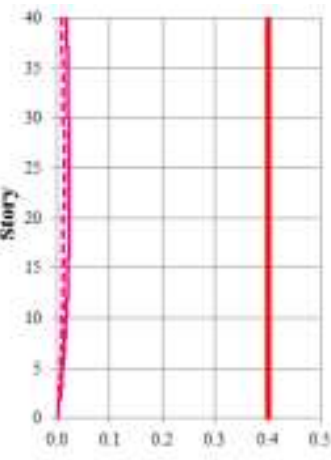

Story Drift (96)

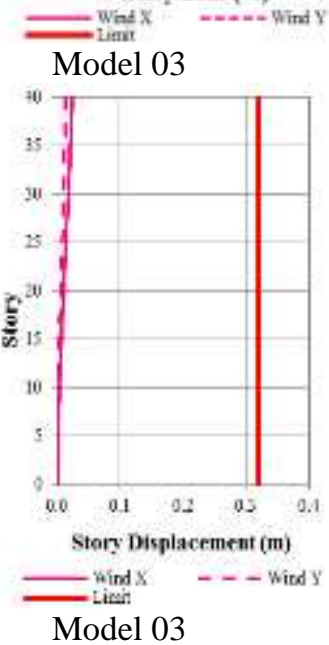

(a) Story displacements in $\mathrm{X}$ and $\mathrm{Y}$ directions

Table 3. Limits in Story Displacement and Drift for Wind and Earthquake

\begin{tabular}{l|l|l}
\hline Limit & Wind $(\mathrm{X}$ and Y) & Earthquake $(\mathrm{X}$ and Y) \\
\hline Story Displacement & $0.32 \mathrm{~m}$ & - \\
Story Drift & $0.4 \%$ & $2 \%$
\end{tabular}

Figure 9 shows the story drift and displacement demands corresponding to the earthquake in $\mathrm{X}$ and $\mathrm{Y}$ axis which will be the same for all building models. For this case also, the story drifts and displacements in the $\mathrm{X}$ axis are greater than the $\mathrm{Y}$ axis and are within the allowable limit. 
Figure 9. (a) Story Displacement(Left) (b) Story Drift corresponding to the Earthquake Loading(Right)
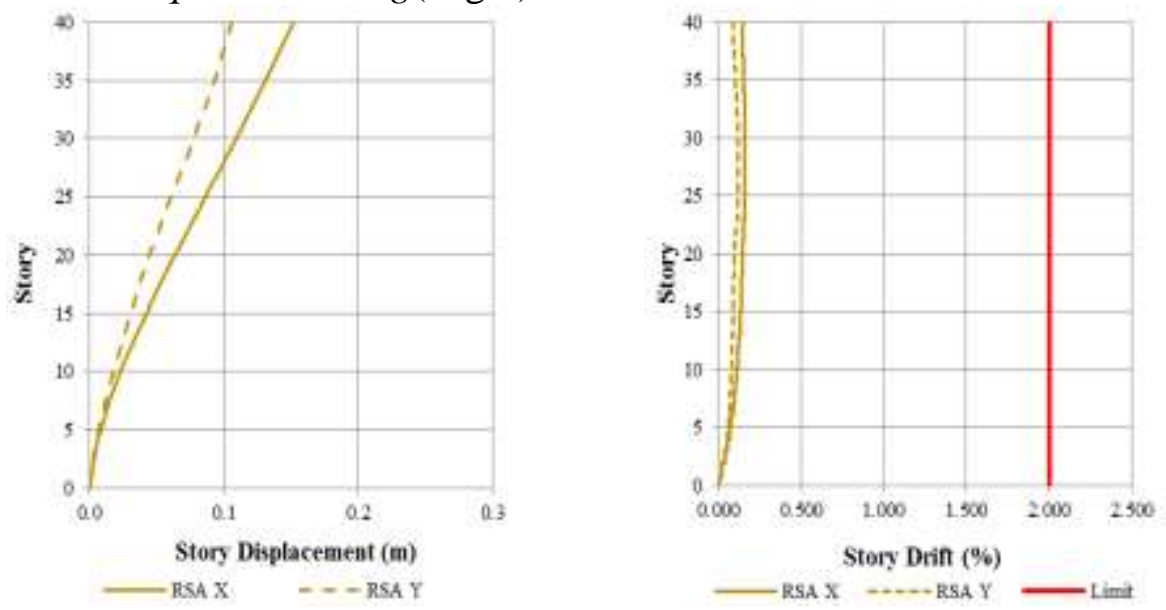

The longitudinal reinforcement percentages that are required for different column types $(\mathrm{C} 800 \times 800, \mathrm{C} 700 \times 700$, C600×600 and C500×500) in different building models are presented in the Figure 10. It is clearly seen that the percentage of reinforcement requirement is gradually decreasing with decreasing wind level except in C500×500 on which the required reinforcement is similar for model 2 and 3 (moderate wind and low wind models) due to the fact that the effect of wind and earthquake is almost the same in both of them. Shear reinforcement does not vary considerably in the three models, because concrete shear capacity is higher in $\mathrm{C} 800 \times 800$ and $\mathrm{C} 700 \times 700$ in all three models. But the columns which are above $20^{\text {th }}$ floor need considerable amount of reinforcement.

Figure 10. Longitudinal Reinforcement (\% to Column Area)

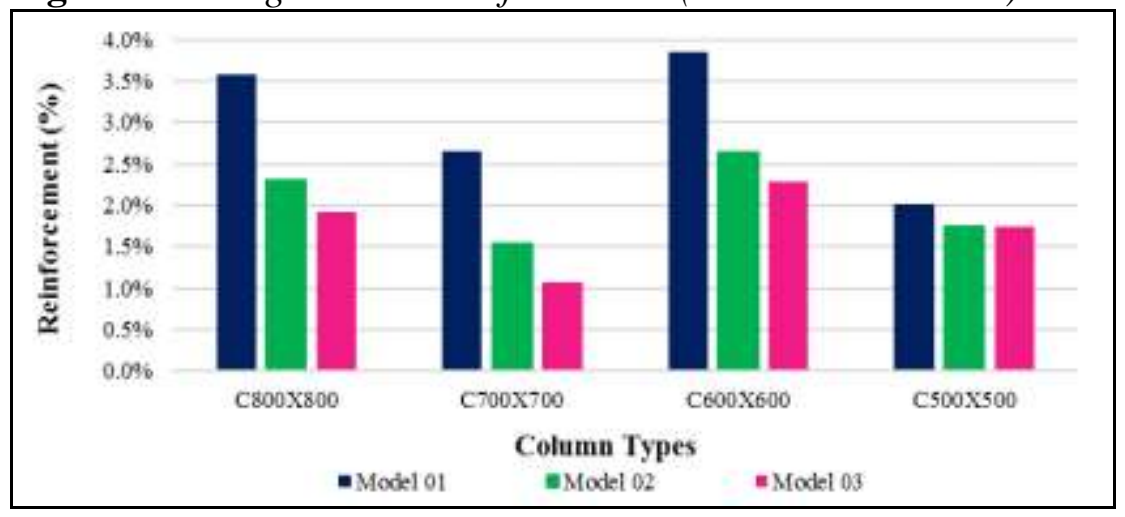

It is apparent that in building model 01 the flexural $\mathrm{D} / \mathrm{C}$ ratio is much higher for wind combo for all the considered columns and in building model 03 the ratio is slightly higher for RSA combo (Figure 11(a)). However, there are slight variations in the amount which the flexural $\mathrm{D} / \mathrm{C}$ ratio of wind combo exceeds the flexural D/C ratio of RSA combo and vice versa depending on the column position. In the building model 02 , it is generally seen that up to story level 20 , the flexural $\mathrm{D} / \mathrm{C}$ ratio of wind combo significantly exceeds the flexural 
D/C ratio of RSA combo and beyond that level both of them are almost the same. Same trend can be seen in the shear demand capacity ratio (Figure 11(b)).

Figure 11. The Distribution of Flexural and (b) Shear D/C Ratios with Story Level in Column C3

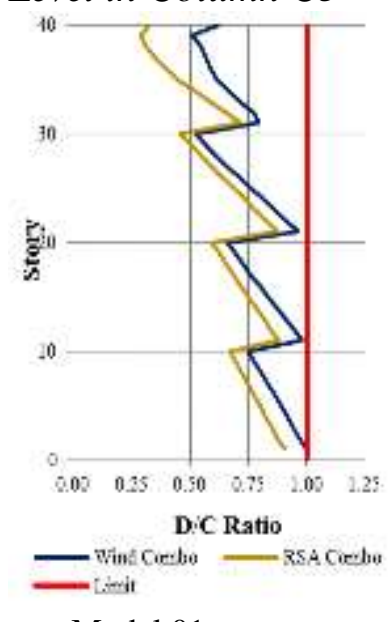

Model 01

(a) Flexural D/C ratios

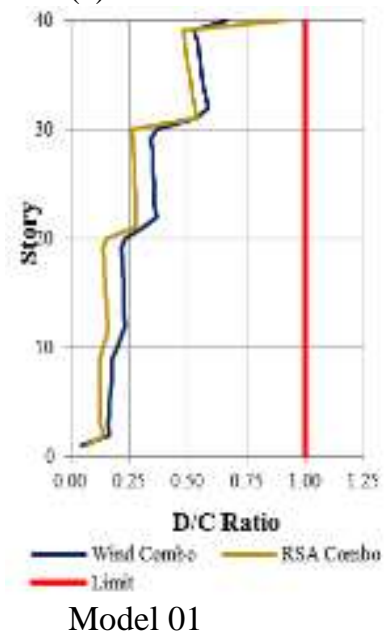

(b) Shear $\mathrm{D} / \mathrm{C}$ ratios
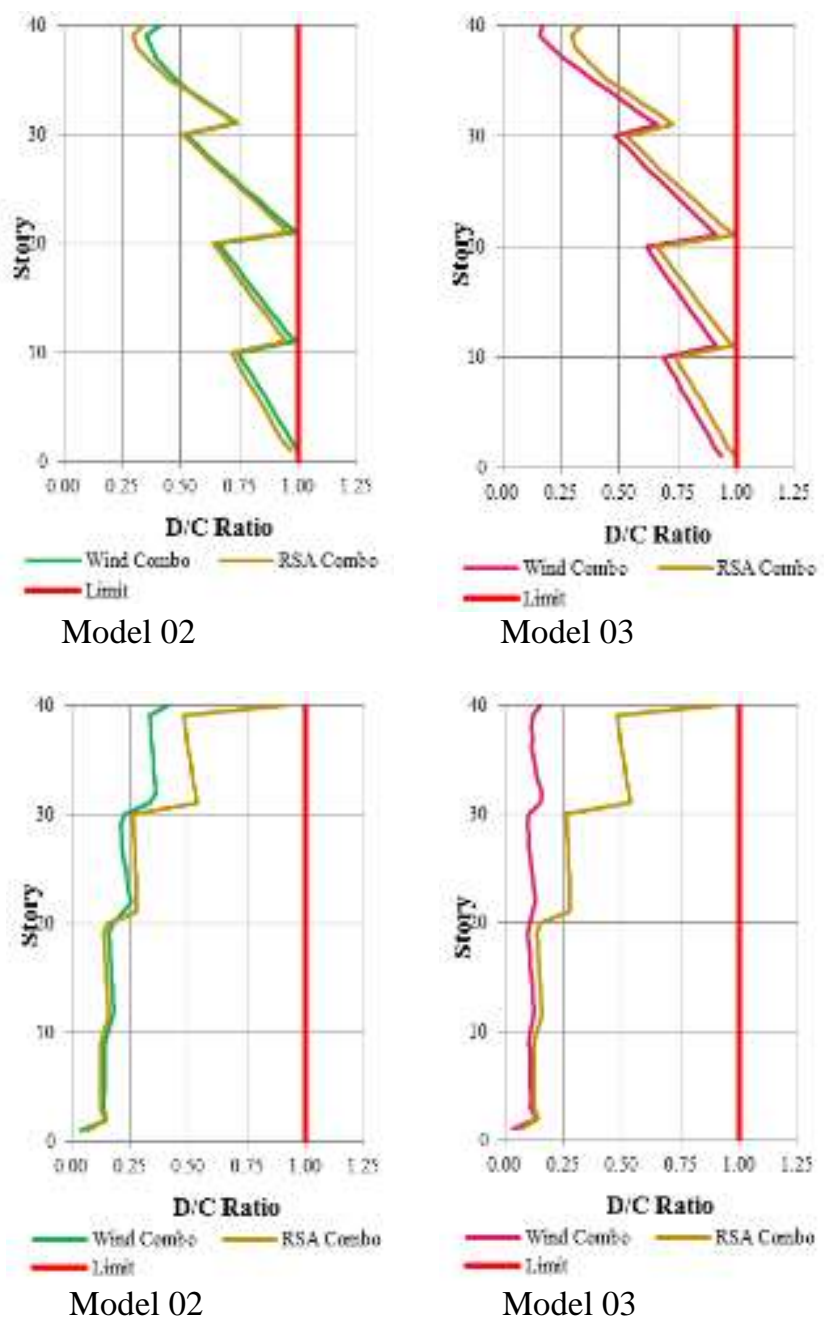

The required reinforcement percentage on different shear wall piers in different building models is presented in the Figure 12. In the first 20 stories, the percentage reinforcement requirement is gradually decreasing with decreasing wind level. In the upper 20 stories, the percentage reinforcement requirement is almost similar in the three building models because the flexural reinforcement is governed by the seismic forces. 
Figure 12. The Shear Wall Reinforcement (\%) in the Three Building Models

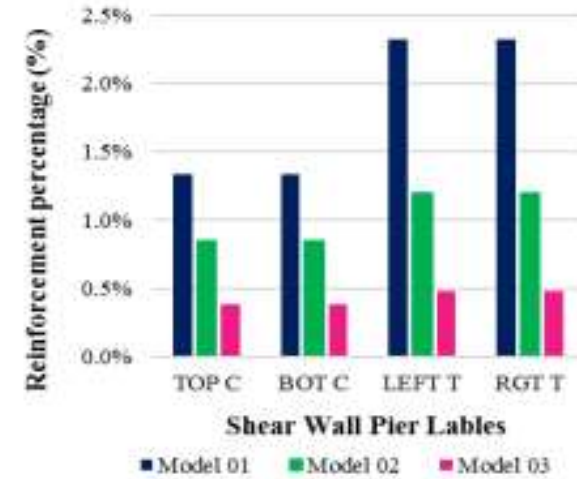

(a) Reinforcement story 1-20

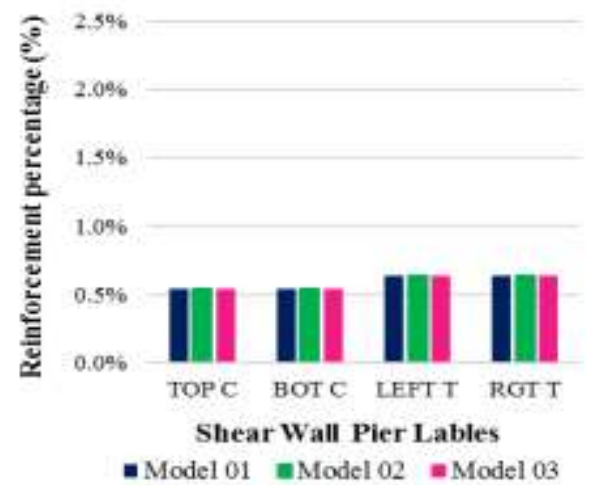

(b) Reinforcement story 21-40

Figure 13. The Distribution of (a) Flexural and (b) Shear D/C Ratios with Story Level in the Pier TOP C
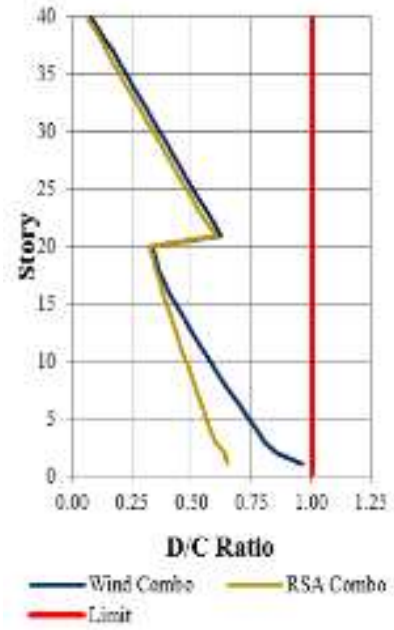

Model 01

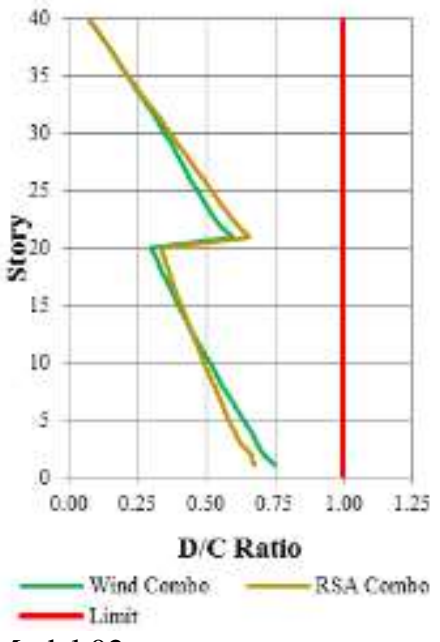

Model 02

(a) The flexural $\mathrm{D} / \mathrm{C}$ ratios
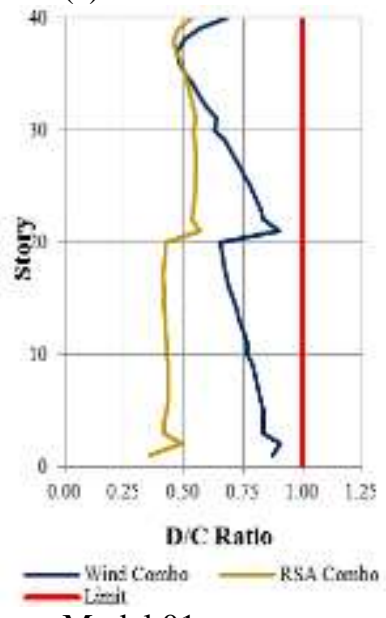

Model 01
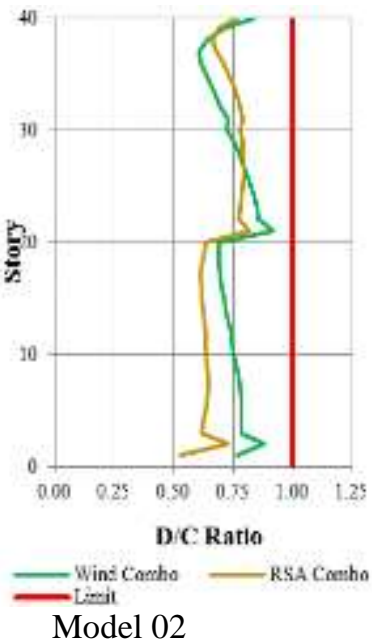

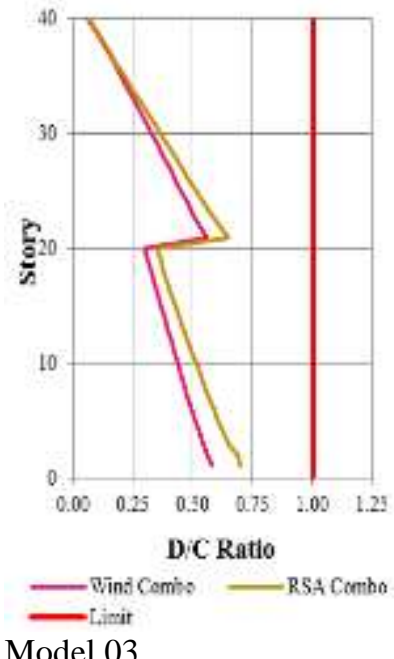

Model 03
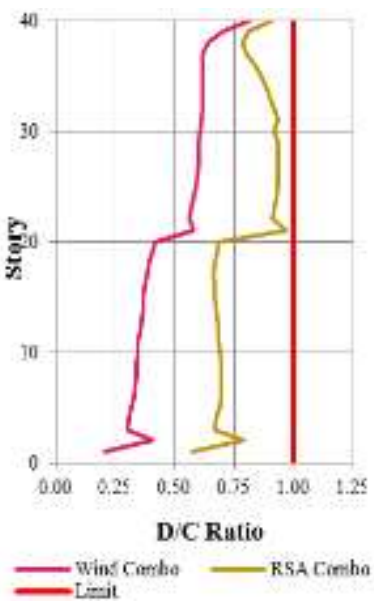

Model 03

(b) The shear $\mathrm{D} / \mathrm{C}$ ratios

The flexural demand-to-capacity $(\mathrm{D} / \mathrm{C})$ ratios of the TOP $\mathrm{C}$ pier is 
presented in Figure 13(a). In all the piers in the building model 03, the flexural D/C ratio is completely governed by the RSA load combinations in each story level. In the building model 02 , in most of the piers, up to story level 10, it is governed by the wind load combinations and then RSA demands exceeds the wind demands. In the building model 01 , in almost every pier, up to story level 20 , it is governed by the wind load combinations and then the flexural D/C ratio for RSA and wind becomes almost the same up to the roof level. The shear $\mathrm{D} / \mathrm{C}$ ratios also show a similar pattern as the flexure D/C ratios (Figure 13(b)).

The required area of reinforcement for the coupling beams was also determined. In each coupling beam, the reinforcement area is gradually decreasing with decreasing wind level, however in CB200×700, reinforcement area for building model 2 and 3 were similar. The calculated amount for top reinforcement area is shown in Figure 14 below.

Figure 14.The Required Reinforcement Area for the Coupling Beams

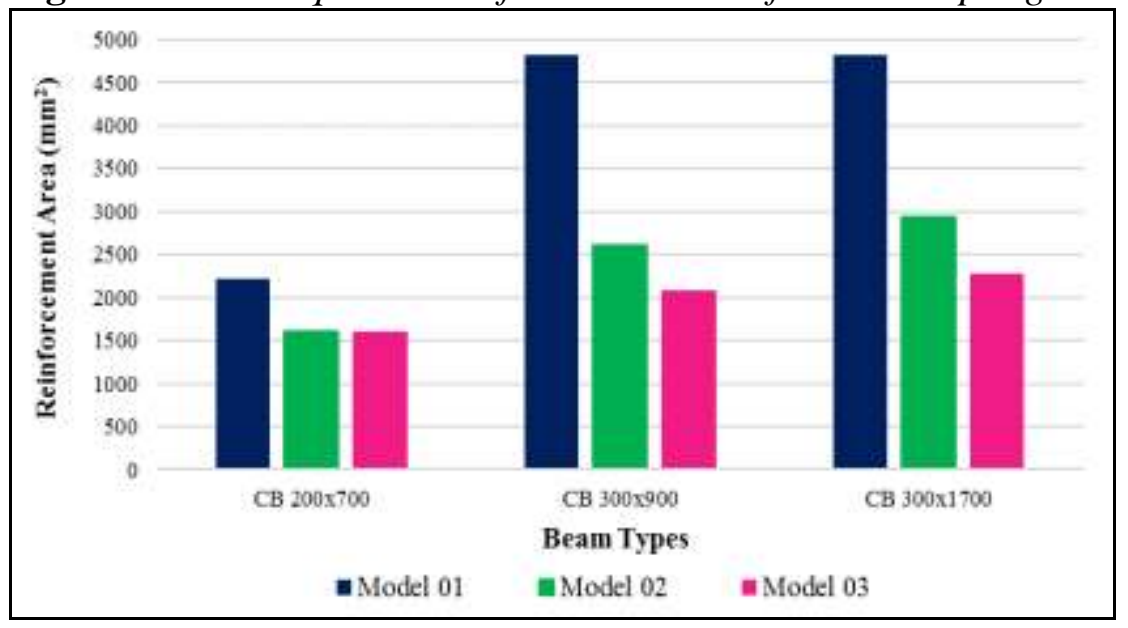

In the building model 03 , the flexural D/C ratio is completely governed by the RSA load combinations in all coupling beams. In the building model 01 it is mostly governed by the wind load combinations with an exception of the uppermost stories (above level 30) where D/C ratio of RSA load combinations slightly exceeds the $\mathrm{D} / \mathrm{C}$ ratio of wind load. In the building model 02 , the flexural D/C ratio is governed by the wind load combinations up to the story level 25, and beyond that it is governed by the RSA load combinations. Figure 15(a) shows the flexure $\mathrm{D} / \mathrm{C}$ ratio for coupling beam $\mathrm{B} 1$. In each building model, the shear D/C ratio for both wind and RSA combo in each coupling beam is showing a similar trend as the flexural D/C ratio (Figure 15(b)).

The reinforcement areas required for different beam types $(400 \times 500$, $500 \times 600,400 \times 600$ and $500 \times 700)$ in different building models are presented in the Figure 16. The Reinforcement area is gradually decreasing with decreasing wind level except in $500 \times 700$ on which the required reinforcement is similar for model 2 and 3 (moderate wind and low wind models) due to the fact that the effect of wind and earthquake is almost the same in both cases. 
Figure 15. The Distribution of (a) Flexural and (b) Shear D/C Ratios in Coupling Beam B1

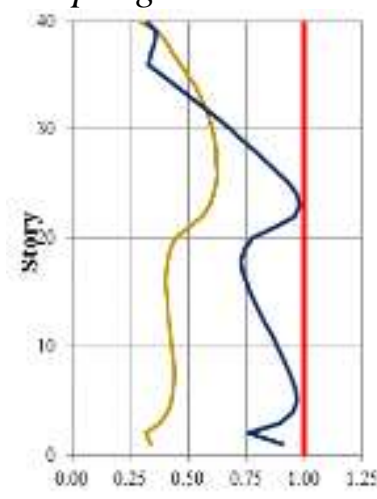

DiC Ratio

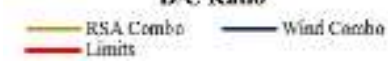

Model 01

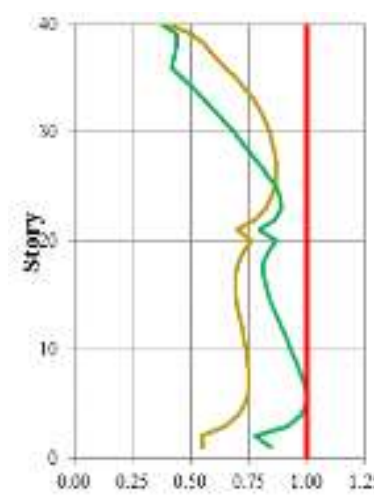

D/C Ratio

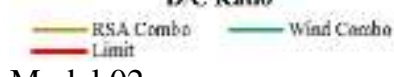

Model 02

(a) The flexural D/C ratios

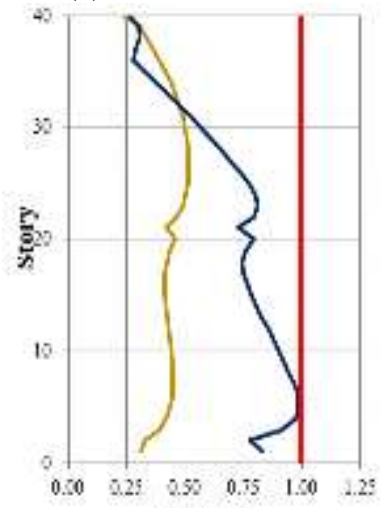

Dic Ratio

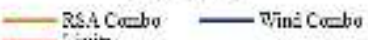

(a) Model 01

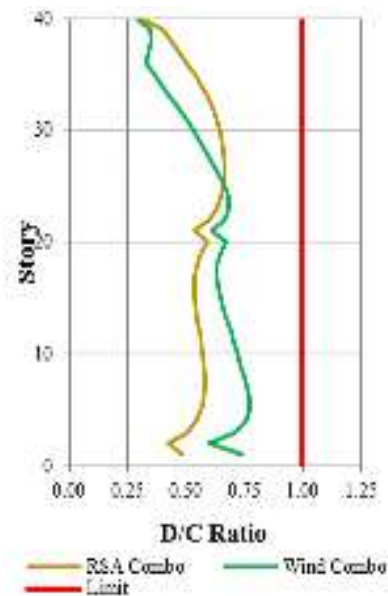

(b) Model 02
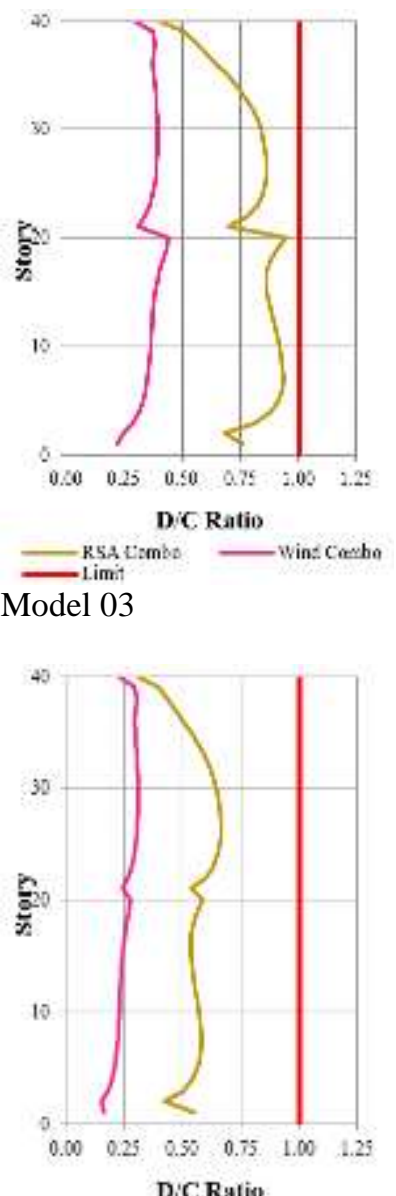

DiC Ratio

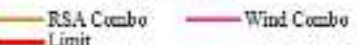

(c) Model 03

(b) The shear $\mathrm{D} / \mathrm{C}$ ratios

Figure 16. The Required Area of Reinforcement in Different Beams for the Three Building Models

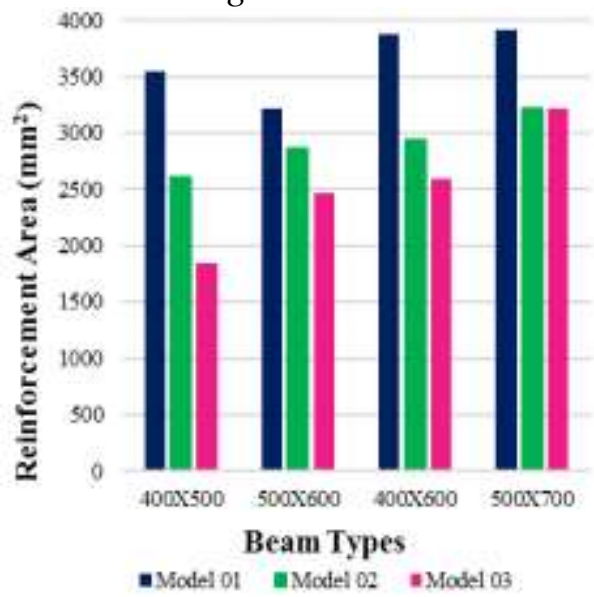

(a) Top reinforcement

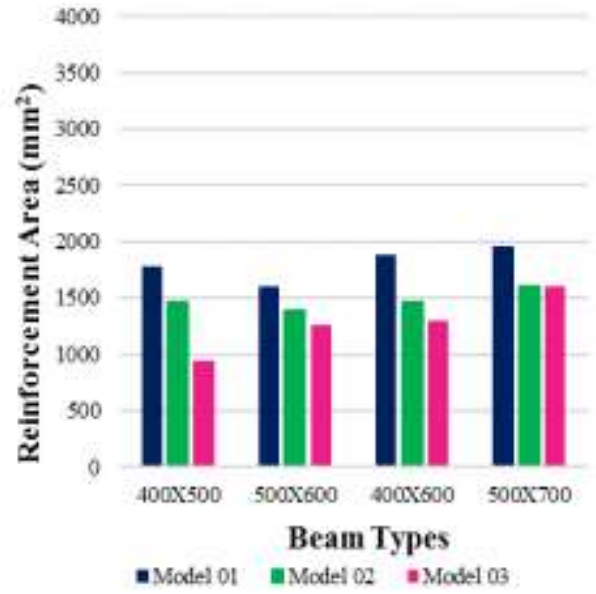

(b) Bottom reinforcement 
The beams were designed considering the maximum demand. The distribution of their flexural D/C ratios with story level is presented in Figure 17. It can be seen that in building model 03 , flexural $\mathrm{D} / \mathrm{C}$ ratio is governed by the RSA load combinations for each beam of interest. Most of the beams in model 01 and 02 , has higher $\mathrm{D} / \mathrm{C}$ ratios from wind combinations, while in some beams in model 2 the D/C ratio from RSA load combinations are governing at higher story levels.

Figure 17. The Distribution of Flexural D/C Ratios with Story Level in Beam B9
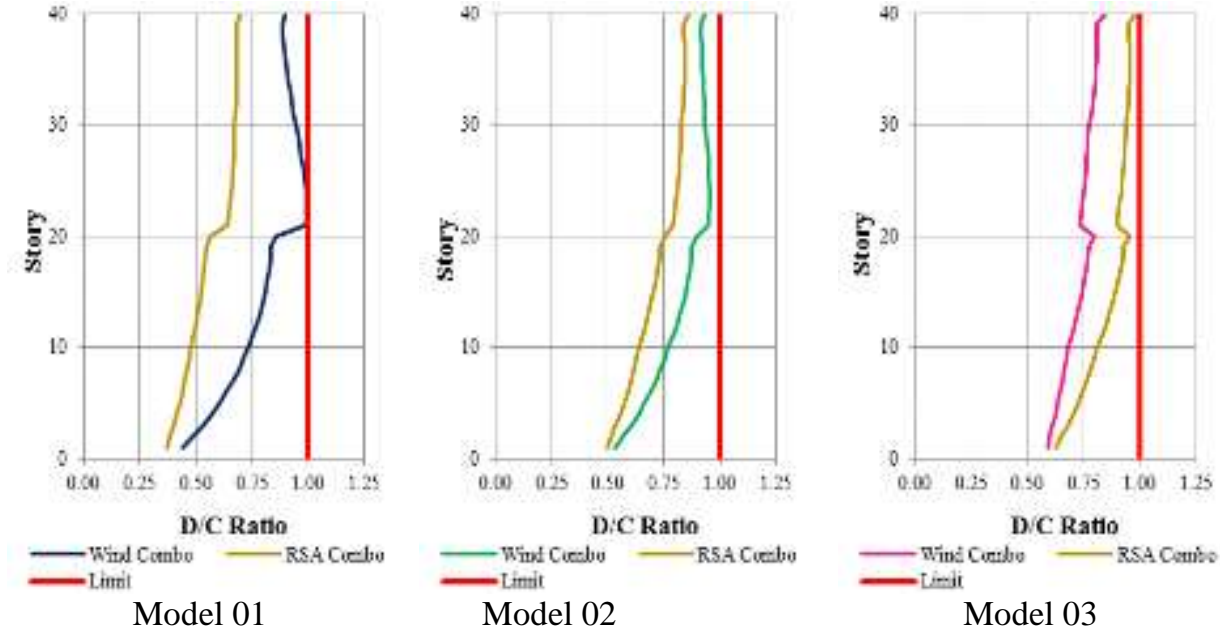

The Seismic Performance Evaluation using the NLRHA Procedure

\section{Overall Inelastic Seismic Demands}

Figure 18 shows the base shear demand obtained from the NLRHA procedure. In order to evaluate the degree of nonlinearity, a linear response history analysis (LRHA) was also performed using the linear elastic model. The linear elastic base shear is compared against the nonlinear base shear responses to assess the extent of nonlinear action experienced by the structure. It can be seen that the inelastic action is increasing from model 1 to model 3 in both $\mathrm{X}$ and $\mathrm{Y}$ directions.

Figure 18. (a) The Base Shear Forces (b) Base Shear Coefficients(\%) for the Linear and Nonlinear Models
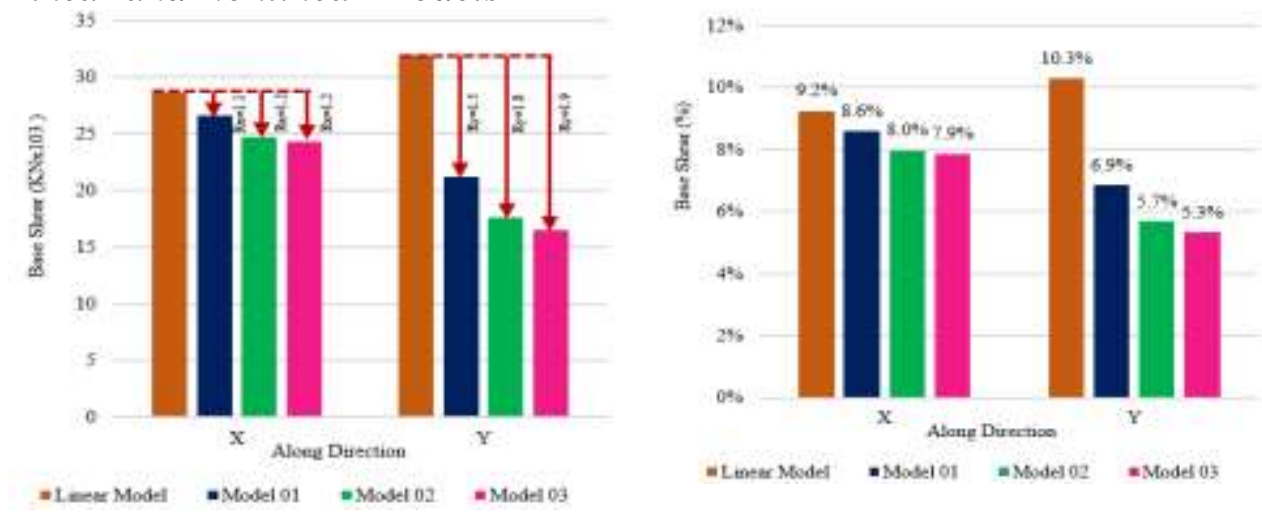

(a)

(b) 
The average story shear obtained from seven ground motion for three building models were compared with the corresponding linear story shears (Figure 19). Story shear in the linear model and the three nonlinear models are not varying much along the $\mathrm{X}$ axis, however, they are varying reasonably along the $\mathrm{Y}$ axis.

Figure 19. The Comparison of Story Shear in Linear and Nonlinear Models

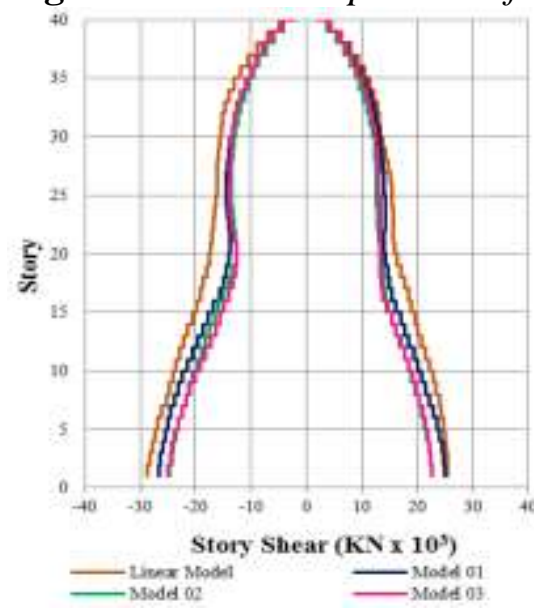

(a) X Direction

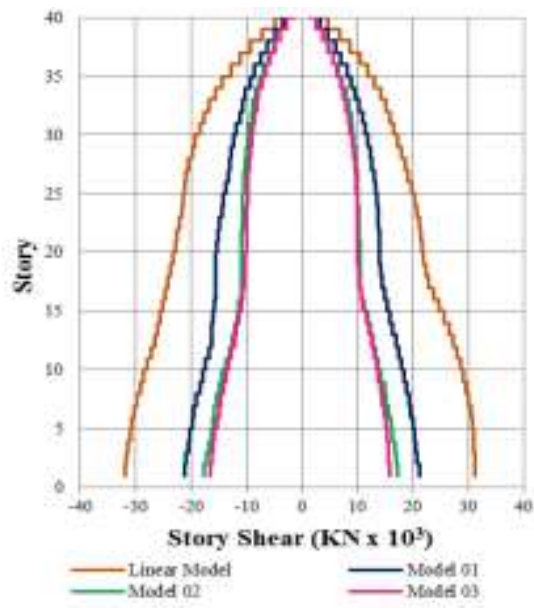

(b) Y Direction

Similarly, the average story moment of seven ground motions for nonlinear model 01, 02 and 03 are compared with corresponding values from the linear model (Figure 20). In this case, a reasonable difference can be seen in the story moment about $\mathrm{X}$ axis. Figure 21 presents the average residual drift for seven ground motions in nonlinear models 01,02 and 03 . The values are found to remain within the acceptable limits.

Figure 20. The Story Moment in Linear and Nonlinear Models

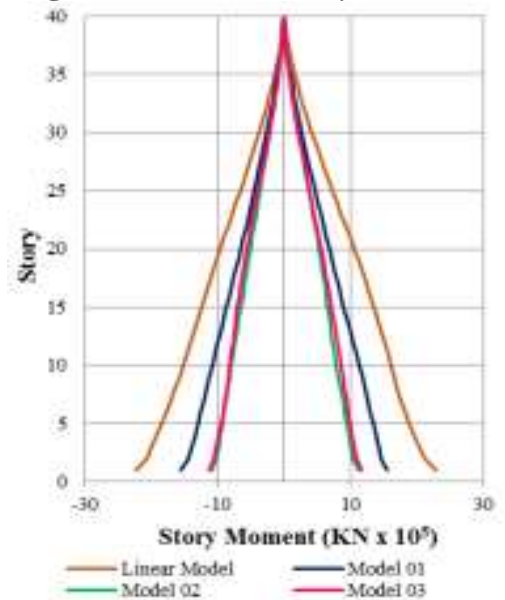

(a) About $\mathrm{X}$ axis

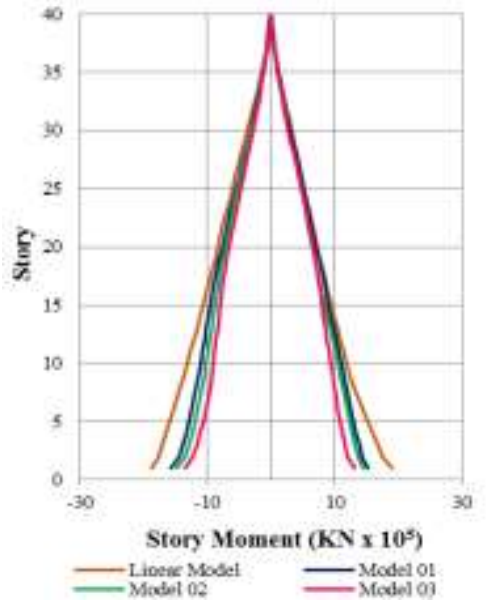

(b) About $\mathrm{Y}$ axis

The average transient drift of seven ground motions in nonlinear model 01, 02 and 03 are also evaluated. The maximum story drift ratios from any ground motion are checked against the limit of 0.045 . It was found that all the transient drift ratios are within the acceptable limits. The comparison between three 
models is shown in Figure 22. The average lateral displacements due to seven ground motion records for all three models are shown in the Figure 23.

Figure 21. Residual Drift in Three Models
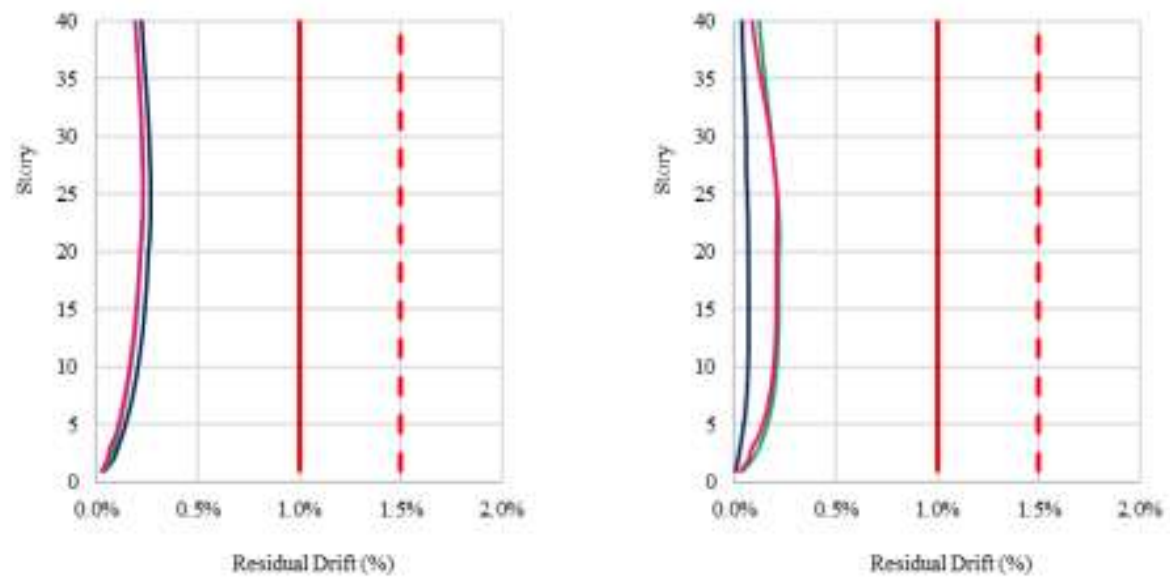

- Model 01 Model 02

(a) X Direction

(b) Y Direction

Figure 22. Story Drift Comparison between Three Models

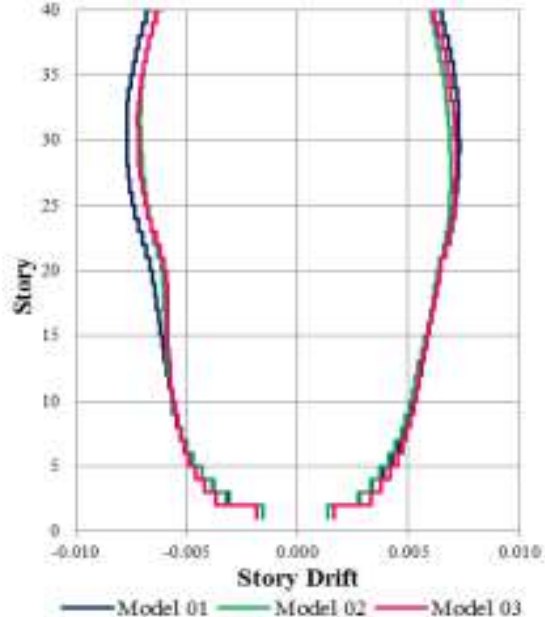

(a) X Direction

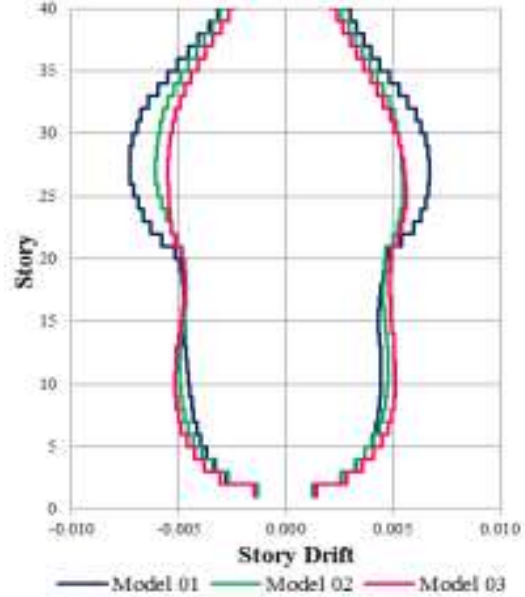

(b) Y Direction 
Figure 23. Displacement Comparison between Three Models

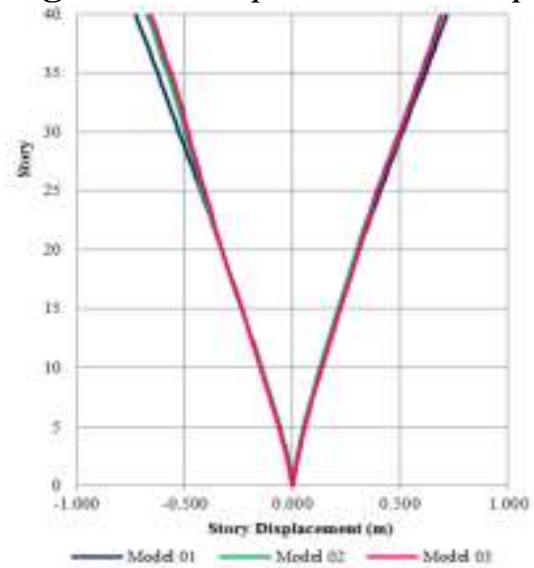

(a) X Direction

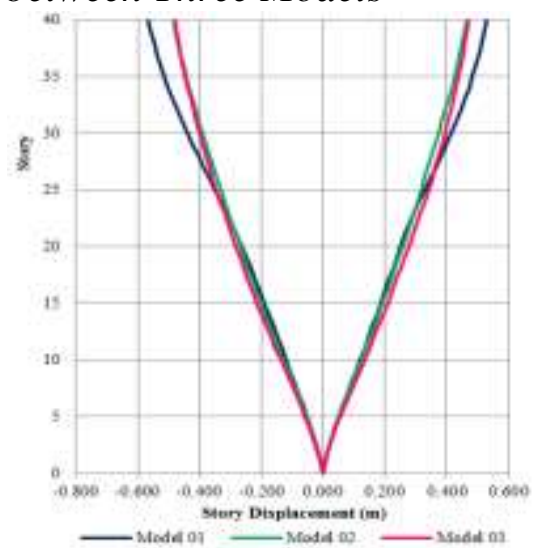

(b) Y Direction

The amount of average energy dissipation from all ground motions is also evaluated for the purpose of comparison. Table 4 shows this comparison of energy dissipated by individual structural components. The dissipated energy in columns is higher in model 01 and similarly, a higher rotation in columns can be seen in the model 01. Likewise, all the nonlinear results can be interpreted in terms of energy dissipation of the elements. Since Model 01 is dissipating less energy, it has less overall damage when compared with other two models. Figure 24 shows the overall energy dissipation in three models.

Table 4. Energy Dissipation Comparison

\begin{tabular}{lccc}
\hline \multirow{2}{*}{ Element Type } & \multicolumn{3}{c}{ Percentage of energy dissipation } \\
\cline { 2 - 4 } Column & Model 01 & Model 02 & Model 03 \\
Shear wall & $0.14 \%$ & $0.08 \%$ & $0.05 \%$ \\
Beam & $0.30 \%$ & $0.22 \%$ & $0.44 \%$ \\
Coupling beam & $0.77 \%$ & $0.77 \%$ & $2.08 \%$ \\
\hline
\end{tabular}

Figure 24. The Overall Energy Dissipation for Three Building Models

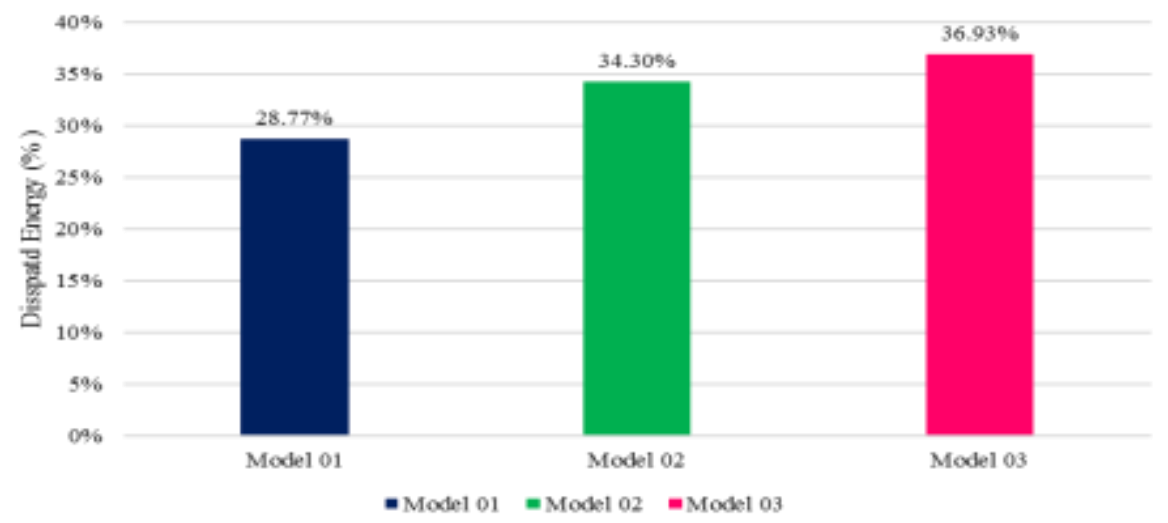




\section{Performance of Individual Components}

The average column rotation for three nonlinear models is shown in Figure 25. The values were examined against the collapse prevention (CP) limit and found to be staying within the limits in each column in each model. It can be seen that the columns in model 01 have more rotation than others towards the top of the building (above $20^{\text {th }}$ floor). However, in lower stories, all three models exhibit the same column rotation. Table 5 shows the column rotation limit for all the columns in each model.

Table 5. The Column Rotation Limits according to ASCE 41-13

\begin{tabular}{lccc} 
Column Types & Model 01 & Model 02 & Model 03 \\
\hline $800 \times 800$ & 0.0110 & 0.0116 & 0.0116 \\
$700 \times 700$ & 0.0127 & 0.0133 & 0.0132 \\
$600 \times 600$ & 0.0115 & 0.0129 & 0.0122 \\
$500 \times 500$ & 0.0294 & 0.0432 & 0.0429 \\
\hline
\end{tabular}

Figure 25.The Comparison of Column Rotation in Three Models

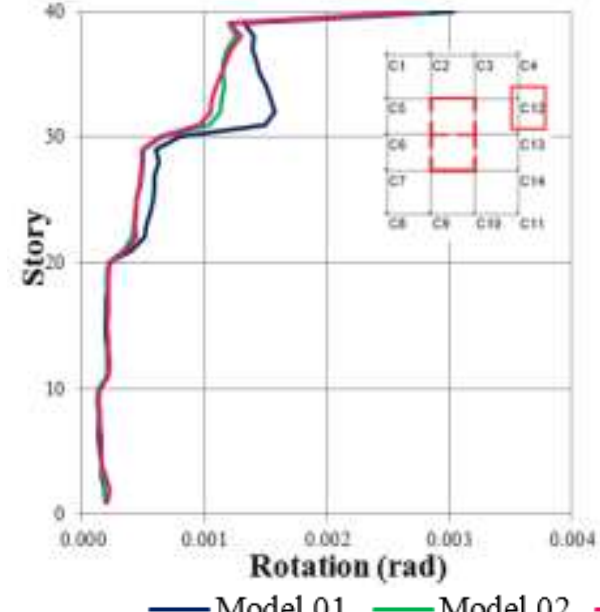

(a) Column C12

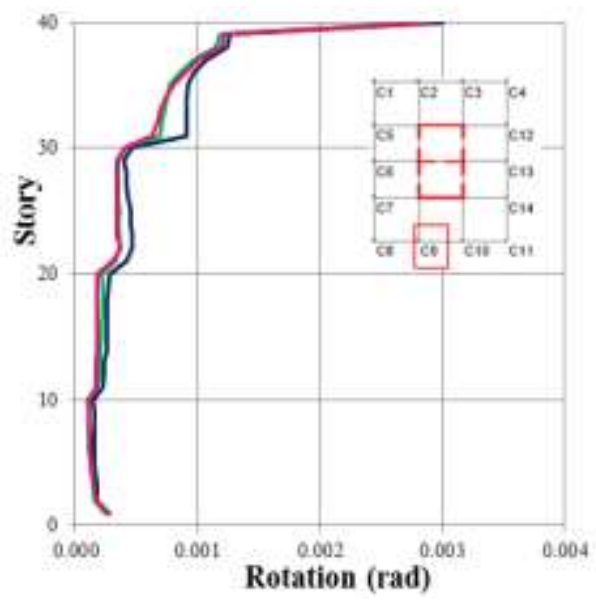

(b) Column C9

The average axial strain values are examined against the limit and it was found that in some locations (G1, G2, G5 and G6), this limit is exceeded in all the building models while in others (G3 and G4), the average stays within the limit. The comparison of axial strains for three models in G3 and G2 locations are shown in the Figure 26. The highest axial strain value at the bottom can be seen in the model 03 . 
Figure 26. The Comparison of Axial Strain in Three Models

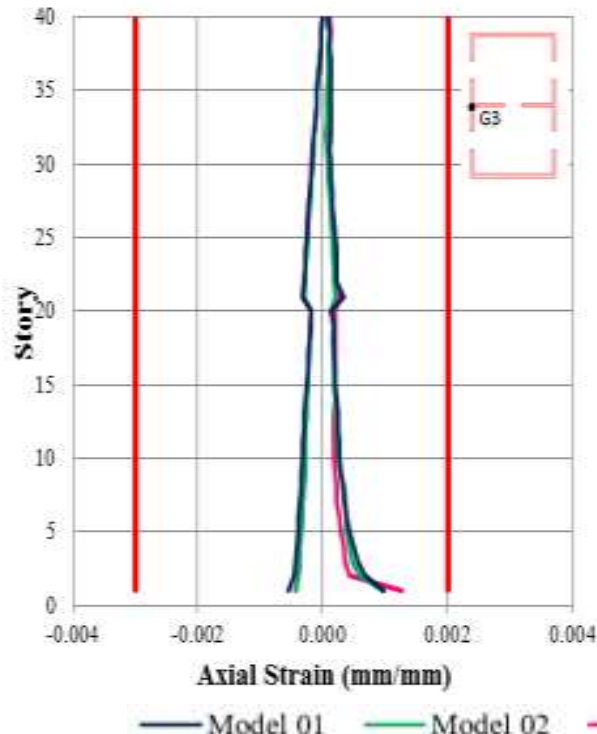

(a) Location G3

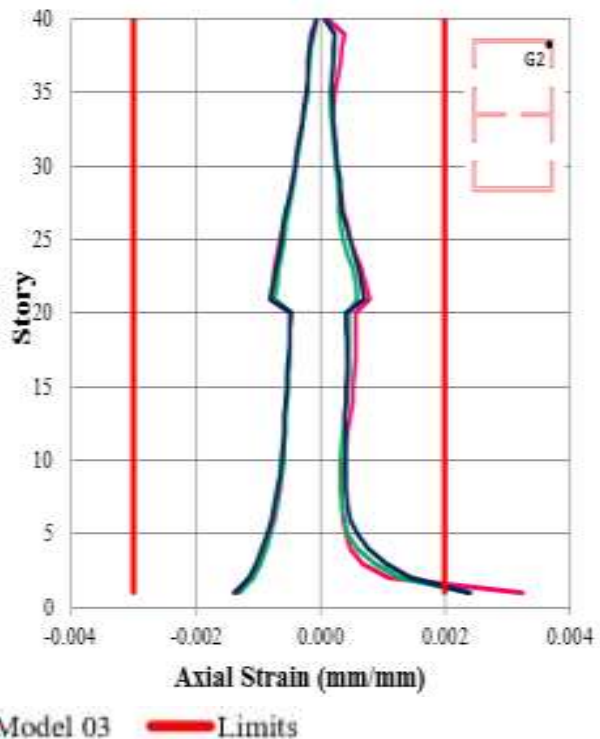

(b) Location $\mathrm{G} 2$

The average values rotations in coupling beams are examined against the limit of 0.5 and it was found that none of the beams exceed this limit in each model. Figure 27 shows the average rotation in coupling beams in three models. As an overall observation, the model 02 shows more rotation than other two models. However, beam the B3 shows more rotation in model 01 at the upper half of the building than others.

Figure 27. The Comparison of Average Rotations in Coupling Beam in Three Models

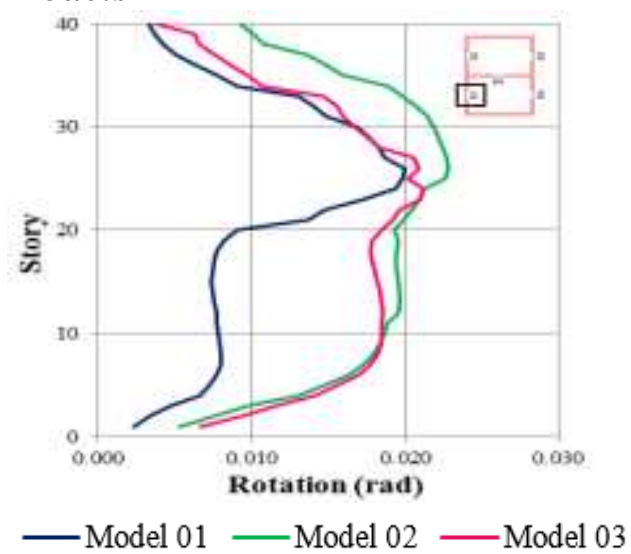

(a) Beam location B1

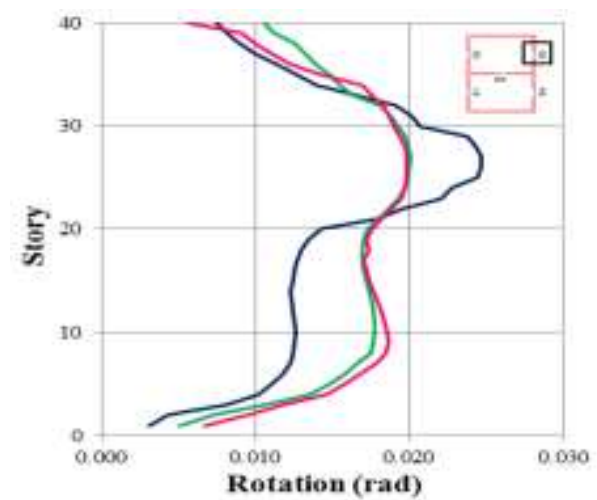

(b) Beam location B3

The average values of rotations in beams is examined against the limits shown in Table 6. It is observed that none of the beams exceed this limit in each model. Limit is not shown in the figure, because limit is too high and rotation cannot be seen. Figure 28 shows the average beam rotation in three models. It can 
be seen that model 03 is showing higher rotation compared to the other two models. However, the values are small and well below the acceptable limits.

Table 6. The Rotation Limits for Beams

\begin{tabular}{lcccccccc}
\hline Model & \multicolumn{1}{l}{ Beam Type } & \multicolumn{1}{c}{$500 \times 600$} & \multicolumn{2}{c}{$400 \times 600$} & \multicolumn{2}{c}{$500 \times 700$} \\
& \multicolumn{2}{c}{ 400x500 } & \multicolumn{2}{c}{500} \\
& Positive & Negative & Positive & Negative & Positive & Negative & Positive & Negative \\
\cline { 2 - 9 } 1 & 0.030 & 0.024 & 0.030 & 0.025 & 0.030 & 0.026 & 0.030 & 0.027 \\
2 & 0.030 & 0.027 & 0.030 & 0.026 & 0.030 & 0.273 & 0.030 & 0.027 \\
3 & 0.030 & 0.028 & 0.030 & 0.027 & 0.030 & 0.027 & 0.030 & 0.026 \\
\hline
\end{tabular}

Figure 28. Beam Rotation Comparison in the Three Models

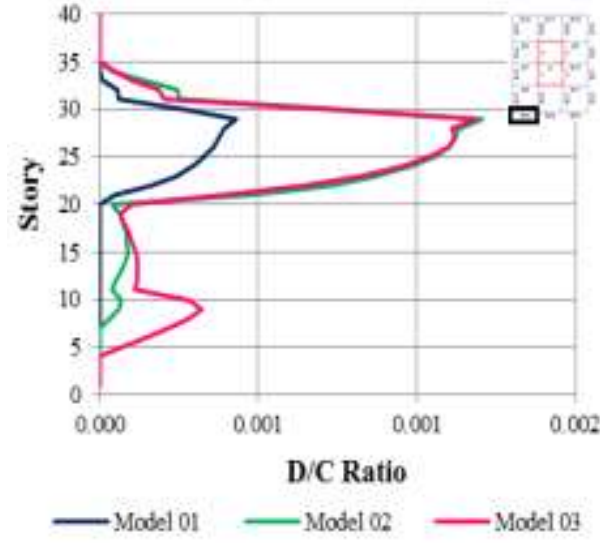

(a) $\mathrm{B} 25$

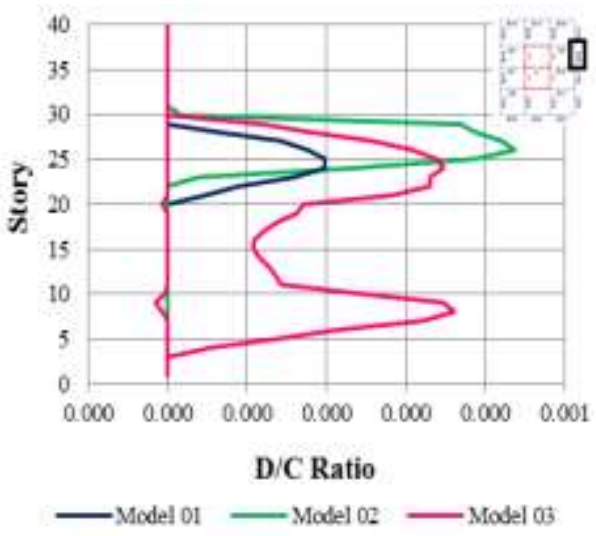

(b) B20

\section{Conclusions}

This study compares the seismic performance of a 40-story high-rise RC building designed based on different levels of lateral wind loads. It is shown that the true nonlinear seismic demands obtained from the detailed NLRHA procedure at the MCE-level seismic hazard are higher than those of both the wind and seismic demand determined by the RSA procedure. This shows that the level of design wind load can alter the seismic performance of high-rise dual system buildings. Therefore, even for the cases where the wind demands control the design of lateral load-resisting system, the detailed performancebased seismic evaluation should be carried out to ensure the overall structural safety and integrity.

\section{References}

Adnan, A. and Suradi, S. 2008. Comparison on the effect of earthquake and wind loads on the performance of reinforced concrete buildings. Paper presented at the $14^{\text {th }}$ World Conference on Earthquake Engineering. 
Ahmed, M. 2011. Optimal reduction of inelastic seismic demands in high-rise RC core wall buildings using energy dissipating devices. Doctoral Dissertation, Structural Engineering, Asian Institute of Technology.

Ahmed, M. andWarnitchai, P. 2012. The cause of unproportionately large higher mode contributions in the inelastic seismic responses of high-rise core-wall buildings. Earthquake Engineering \& Structural Dynamics, 41(15), 2195-2214.

Aly, A. M. and Abburu, S. 2015. On the Design of High-Rise Buildings for Multihazard: Fundamental Differences between Wind and Earthquake Demand. Shock and Vibration, 501, 148681.

ASCE/SEI 41-06.(2006). Seismic evaluation and retrofit of existing buildings. https:// doi.org/10.1061/9780784408841. American Society of Civil Engineers (ASCE).

Chopra, A. K. 2007. Dynamics of Structures: Theory and Applications to Earthquake Engineering. Prentice Hall: Upper Saddle River, NJ.

Computers and Structures (CSI), Inc. 2016. ETABS Extended 3D Analysis of Building Systems Software, Nonlinear Version 9.0.0. Computers and Structures, Inc.: Berkeley, CA.

Computers and Structures (CSI), Inc. 2006. Perform 3D, Nonlinear Analysis and Performance Assessment for 3D Structures User Guide, Version 4. Computers and Structures, Inc., Berkeley, CA.

COSMOS.1999. Consortium of Organizations for Strong-Motion Observation Systems. COSMOS Virtual Data Center (VDC).

CTBUH.2016. CTBUH Criteria for Defining and Measuring Tall Buildings. Retrieved from http://www.ctbuh.org

DPT 1302 (2009) Seismic resistant design of buildings and structures. Department of Public Works and Town \& Country Planning, Ministry of Interior, p. 125 [in Thai].

Hancock, J., Watson-Lamprey, J., Abrahamson, N. A., Bommer, J. J., Markatis, A., McCOY, E. and Mendis, R. 2006. An improved method of matching response spectra of recorded earthquake ground motion using wavelets. Journal of earthquake engineering, 10(spec01), 67-89.

Hoang, T. (2011).Effect of the wind resistant design on the seismic design of high-rise buildings with RC core walls in low to moderate seismicity regions.Master Thesis, Structural Engineering, Asian Institute of Technology.

Holmes, J. D. 2017. Wind loading of structures.CRC press.

LATBDSC, 2005. An Alternative Procedure for Seismic Analysis and Design of Tall Buildings Located in Los Angeles Region, A Consensus Document, Los Angeles Tall Buildings and Structural Design Council, 2005.

Klemencic, R., Fry, J. A. and Hooper, J. D. 2006. Performance-based design of tall reinforced concrete ductile core wall systems.The structural design of tall and special buildings, 15(5), 571-579.

Klemencic, R., Fry, J. A., Hooper, J. D. and Morgen, B. G. 2007.Performance-based design of ductile concrete core wall buildings - issues to consider before detailed analysis.The structural design of tall and special buildings, 16(5), 599-614.

Mander, J. B., Priestley, M. J. N. and Park, R. 1988.Theoretical stress-strain model for confined concrete. J. Struct. Eng. ASCE. 114: 1804-1826.

Moehle, J. P. 2008. Performance-based seismic design of tall buildings in the US. Paper presented at the $14^{\text {th }}$ World Conference on Earthquake Engineering (CD), Beijing, China.

Naeim, F. 2010. Performance Based Seismic Design of Tall Buildings. Earthquake Engineering in Europe, 147-169. 
PEER. 2005. Pacific Earthquake Engineering Research (PEER) - Strong ground motion database.

Wallace, J. W. 2007. Modelling issues for tall reinforced concrete core wall buildings. The structural design of tall and special buildings, 16(5), 615-632.

Zekioglu, A., Willford, M., Jin, L., and Melek, M. 2007. Case study using the Los Angeles tall buildings structural design council guidelines: 40-storey concrete core wall building. Structural Design of Tall and Special Buildings, 16(5), 583. 
